University of Massachusetts Amherst

ScholarWorks@UMass Amherst

Chemical Engineering Faculty Publication

Series

2020

\title{
The benefit of poor mixing: kinetics of coacervation
}

\author{
Whitney C. Blocher McTigue \\ University of Massachusetts Amherst \\ Elizabeth Voke \\ University of Massachusetts Amherst \\ Li-Wei Chang \\ University of Massachusetts Amherst \\ Sarah L. Perry \\ University of Massachusetts Amherst
}

Follow this and additional works at: https://scholarworks.umass.edu/che_faculty_pubs

\section{Recommended Citation}

Blocher McTigue, Whitney C.; Voke, Elizabeth; Chang, Li-Wei; and Perry, Sarah L., "The benefit of poor mixing: kinetics of coacervation" (2020). Physical Chemistry Chemical Physics. 891.

https://doi.org/10.1039/D0CP03224G

This Article is brought to you for free and open access by the Chemical Engineering at ScholarWorks@UMass Amherst. It has been accepted for inclusion in Chemical Engineering Faculty Publication Series by an authorized administrator of ScholarWorks@UMass Amherst. For more information, please contact scholarworks@library.umass.edu. 


\title{
The Benefit of Poor Mixing: Kinetics of Coacervation
}

\author{
Whitney C. Blocher McTigue, Elizabeth Voke, Li-Wei Chang, and Sarah L. Perry* \\ Department of Chemical Engineering, University of Massachusetts Amherst \\ *Correspondence: perrys@engin.umass.edu
}

\begin{abstract}
:
Complex coacervation has become a prominent area of research in the fields of food science, personal care, drug stabilization, and more. However, little has been reported on the kinetics of assembly of coacervation itself. Here, we describe a simple, low-cost way of looking at the kinetics of coacervation by creating poorly mixed samples. In particular, we examine how polymer chain length, the patterning and symmetry of charges on the oppositely charged polyelectrolytes, and the presence of salt and a zwitterionic buffer affect the kinetics of complex coacervation. Our results suggest an interesting relationship between the time for equilibration and the order of addition of polymers with asymmetric patterns of charge. Furthermore, we demonstrated that increasing polymer chain length resulted in a non-monotonic trend in the sample equilibration times as a result of opposing factors such as excluded volume and diffusion. We also observed differences in the rate of sample equilibration based on the presence of a neutral, zwitterionic buffer, as well as the presence and identity of added salt, consistent with previous reports of salt-specific effects on the rheology of complex coacervates. While not a replacement for more advanced characterization strategies, this turbidity-based method could serve as a screening tool to identify interesting and unique phenomena for further study.
\end{abstract}




\section{Table of Contents:}

The Benefit of Poor Mixing: Kinetics of Coacervation ............................................................... 1

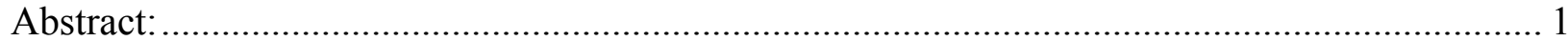

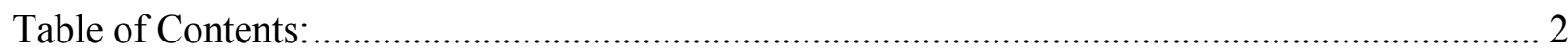

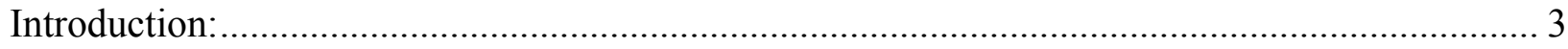

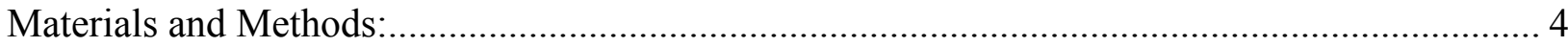

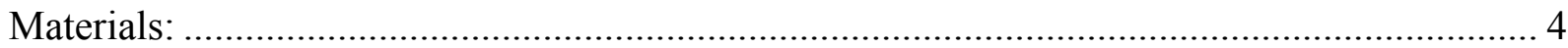

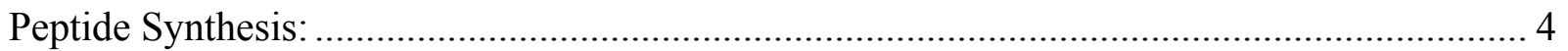

Coacervate Preparation: .................................................................................... 5

Turbidity Analysis: ...................................................................................... 6

Data Analysis: .......................................................................................... 7

Experimental Results and Discussion: ..................................................................... 7

Coacervation by Hand and by Machine: .................................................................. 7

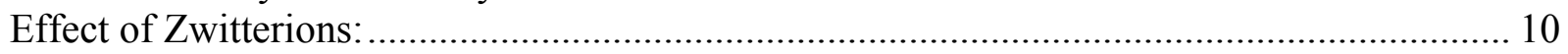

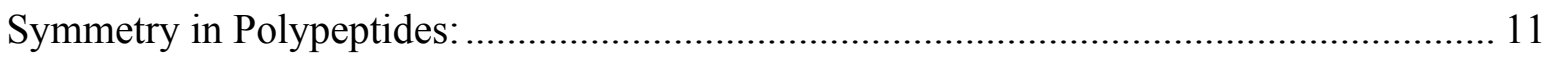

Asymmetry in Polypeptides:....................................................................................... 12

Is This Just Diffusion? Chain Length of Polypeptides: ........................................................... 13

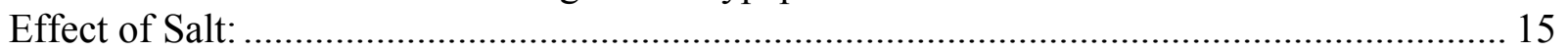

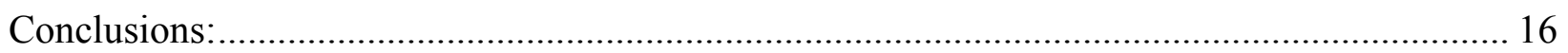

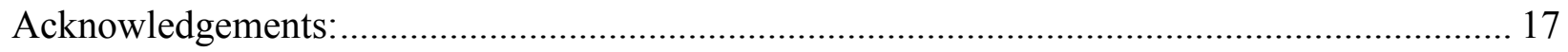

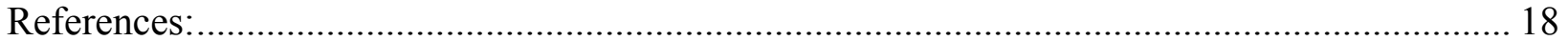




\section{Introduction:}

Complex coacervation is an associative, liquid-liquid phase separation phenomenon driven by an initial electrostatic attraction between oppositely charged macroions. ${ }^{1-7}$ This attraction is followed by entropic gains from the release of small, bound counter-ions and the restructuring of water molecules. ${ }^{8-11}$ Phase separation typically results in the formation of coacervates as a dispersion of macromolecule-rich (e.g., polymer, protein, etc.) droplets in equilibrium with a macromolecule-poor phase, called the supernatant. ${ }^{8,9,12-21}$ The scope of coacervation has expanded from its original focus on proteins and polysaccharides ${ }^{22-24}$ and their applications in food to include polynucleotides, ${ }^{25-30}$ synthetic polymers, ${ }^{31-37}$ surfactants, ${ }^{38-45}$ nanoparticles, ${ }^{46,47}$ and other hierarchical assemblies ${ }^{48-55}$ and its use has extended into fields such as adhesives, ${ }^{56-71}$ drug delivery, ${ }^{2,12,15,25,27,28,32,34,72-88}$ nano/bio-reactors, ${ }^{31,33,89-91}$ and cellular biology. ${ }^{25,92-109}$

Much of the utility of coacervates has come from their ability to effectively encapsulate cargo and/or respond to their environment. Therefore, the vast majority of studies on coacervate materials require mapping out some aspect of the phase behavior of these materials. While a number of recent reports have quantitatively mapped out the entire two-phase region, ${ }^{110-114}$ most studies take advantage of turbidity or light scattering to simply determine conditions where coacervates form. ${ }^{8,14,17,115-118}$ These characterizations of phase behavior can often be accelerated through the use of automation, particularly by helping decrease the required sample volumes. This need for small sample volumes is particularly acute in many biologically-inspired or biorelevant systems where it can be challenging to obtain large quantities of material.

In contrast to the number of studies aimed at characterizing the thermodynamic phase behavior of complex coacervation, there are significantly fewer efforts that look into the dynamic nature of coacervate formation. There are kinetic studies dedicated to the formation of polyelectrolyte complexes broadly, ${ }^{119-125}$ as well as on liquid complex coacervation specifically. ${ }^{46,80,126-128}$ The majority of studies take advantage of techniques such as turbidity, ${ }^{46}$ light scattering, ${ }^{122,123,127}$ or small angle X-ray scattering ${ }^{119}$ to track coacervate evolution. These studies tend to take advantage of fast mixing, such that the kinetics of complexation can be monitored after both polyelectrolytes have come into contact with each other. ${ }^{46,119,121-124,127}$ Much of this work focuses on the nucleation and early-time evolution of complexes in dilute solution, looking at parameters such as salt, $\mathrm{pH}$, and mixing/charge ratio. ${ }^{46,119,121-124,127}$ However, the evolution of coacervate materials in formulations relevant for real-world applications can be very different than what is observed in well-mixed laboratory samples. Here, complicating factors such as differences in the concentration of the various components and/or the order of component addition ${ }^{126,127,129}$ can have a significant effect on the resulting product and/or the time needed for it to equilibrate. While such formulation questions can be answered via large-scale direct experiments, we discuss a method that takes advantage of the types of turbidity experiments that researchers are already performing to answer these questions at a much smaller scale.

Here, we describe a simple, method for studying the kinetics of coacervate formulation by tracking the time evolution of the turbidity of dilute, poorly mixed coacervating samples prepared at a range of polycation/polyanion ratios. We examine the kinetics of coacervation for polypeptides with a range of chain lengths and sequences. We also study how the addition of salt, the identity of the salts, and the presence of a zwitterionic buffer affects the kinetics of complexation and the sensitivity of these parameters to the order of polymer addition to the sample. 


\section{Materials and Methods:}

\section{Materials:}

Abbreviations for reagents are as follows: tert-butoxycarbonyl (Boc); 9fluorenylmethoxylcarbonyl (Fmoc); t-butyl (tBu); trifluoroacetic acid (TFA); triisopropylsilane (TIPS); N,N-dimethylformamide (DMF); dichloromethane (DCM); N,Ndiisopropylcarbodiimide (DIC); lysine (Lys or K); glutamate (Glu or E); glycine (Gly or G); ethyl (hydroxyimino)cyanoacetate (Oxyma); 4-(2-hydroxyethyl)-1-piperazineethanesulfonic acid (HEPES).

Sequencing grade DMF, GC/MS grade DCM, TFA, ethyl ether anhydrous (BHT stabilized), methanol and acetonitrile (HPLC grade) were purchased from Fisher Scientific. Piperidine, $\alpha-$ cyano-4-hydroxycinnamic acid, isopropanol (99\%) was purchased from Sigma Aldrich. DIC (99\%), TIPS (98\%) was purchased from Acros Organics. Rink amide MBHA resin (loading level $0.32 \mathrm{mmol} / \mathrm{g}$ ), Fmoc- $L$-Lys(Boc)-OH, Fmoc- $D$-Lys(Boc)-OH, Fmoc- $L-\mathrm{Glu}(\mathrm{tBu})-\mathrm{OH}$, Fmoc- $D$ $\mathrm{Glu}(\mathrm{tBu})-\mathrm{OH}, \mathrm{Fmoc}-\mathrm{Gly}-\mathrm{OH}$, and Oxyma were all purchased from Peptide Solutions, LLC. All water was dispensed from a Milli-Q water purification system at a resistivity of $18.2 \mathrm{M} \Omega . \mathrm{cm}$ (Millipore).

Zwitterionic HEPES buffer ( $\geq 99 \%$ ) was purchased as a powder from Fisher Scientific and made into a $0.5 \mathrm{M}$ stock solution adjusted to $\mathrm{pH}$ 7.0. Sodium chloride, potassium chloride, and sodium bromide were purchased as powders from Sigma Aldrich. Potassium bromide was purchased from Fisher Scientific as a powder. All salt stocks were made at $0.5 \mathrm{M}$ and adjusted to $\mathrm{pH}$ 7.0.

\section{Peptide Synthesis:}

Polypeptides with $\mathrm{N}=50$ were prepared using standard Fmoc-based solid-phase synthesis on a Liberty Blue automated microwave peptide synthesizer from CEM, Ltd. ${ }^{130}$ Deprotection and coupling were performed under microwave irradiation on a Rink amide MBHA resin with $0.2 \mathrm{M}$ Fmoc and Boc protected lysine (Fmoc- $L$-Lys(Boc)-OH, Fmoc- $D$-Lys(Boc)-OH), Fmoc and tBu protected glutamate (Fmoc- $L-\mathrm{Glu}(\mathrm{tBu})-\mathrm{OH}$, Fmoc- $D-\mathrm{Glu}(\mathrm{tBu})-\mathrm{OH})$, and Fmoc protected glycine (Fmoc-Gly-OH) in DMF. 20\% Piperidine in DMF was used for Fmoc deprotection. DIC and Oxyma in a $0.5 \mathrm{M}$ and $1.0 \mathrm{M}$ concentration in DMF were used as activator and base, respectively.

Cleavage from the resin and side-chain deprotection was in performed using $10 \mathrm{~mL}$ of TFA/water/TIPS in the volume ratio of $95 / 2.5 / 2.5$ for 3 hours at room temperature while bubbling with carbon dioxide. The cleaved product and resin were separated by filtration. The crude peptide was then precipitated into $40 \mathrm{~mL}$ of cold (stored at $-80^{\circ} \mathrm{C}$ ) anhydrous ethyl ether. The mixture was then centrifuged for $5 \mathrm{~min}$ at 5,000 rpm (Sorvall Legend X1R Centrifuge, Thermo Fisher Scientific, Inc.). The supernatant was decanted and a second round of precipitation and centrifugation was performed. The crude product was then dried in vacuo in a desiccator overnight. All glutamate polymers were $\mathrm{pH}$ balanced after synthesis for solubility and then lyophilized.

Characterization of the final product was performed via a Bruker UltrafleXtreme (Fremont, CA, USA) matrix-assisted laser desorption/ionization time of flight mass spectrometer (MALDITOF). Samples of the peptide were mixed with matrix solution (approximately $50 \mathrm{mg} / \mathrm{mL} \alpha$ cyano-4-hydroxycinnamic acid dissolved in 1:1 mixture of water and acetonitrile with $0.05 \%$ 
TFA) in 1:1 ratio to reach a final concentration of approximately $7.5 \mathrm{mM}$ peptide.

Poly(glutamate) with degree of polymerization $\mathrm{N}=50$ was synthesized using amino acids of alternating chirality $\left(D\right.$ and $L$ ) to mitigate inter-peptide hydrogen bond formation, ${ }^{10,13,131,132}$ while poly(lysine) with $\mathrm{N}=50$ was synthesized only using amino acids of $L$ chirality. Sequencedefined poly(lysine-co-glycine) $\left(\mathrm{K}_{\mathrm{x}} \mathrm{G}_{\mathrm{y}}\right)_{\mathrm{N}}$ and poly(glutamate-co-glycine) $\left(\mathrm{E}_{\mathrm{x}} \mathrm{G}_{\mathrm{y}}\right)_{\mathrm{N}}$ peptides were synthesized with a degree of polymerization $\mathrm{N}=50$. Thus, all peptides include the chargepatterned blocks of 48 amino acids described by the block size, and are capped on each terminus by a single amino acid (K, E, or G, Table 1$)$. For a block size of 16 , the lysine or glutamate portions of the peptide were synthesized using amino acids of alternating chirality ( $D$ and $L$ ) to mitigate inter-peptide hydrogen bond formation. ${ }^{10,13,131,132}$ This use of alternating chirality was only implemented for the longest block size because of the tendency for complexing peptides to form $\beta$-sheets when a continuous run of more than 7-8 chiral amino acids is present. ${ }^{10,132}$ Lysine residues exist as TFA salts, while glutamate residues are present as sodium salts.

Table 1. Molecular sequence for poly(lysine-co-glycine) or poly(glutamate-co-glycine), denoting lysine or glutamate with an X, peptides with degree of polymerization $\mathrm{N}=50$.

\begin{tabular}{c|c}
\hline Block Size & $\begin{array}{c}\text { Polypeptide } \\
\text { Sequence }\end{array}$ \\
\hline 2 & $(\mathrm{XG})_{25}$ \\
4 & $\mathrm{G}(\mathrm{XXGG})_{12} \mathrm{X}$ \\
8 & $\mathrm{G}\left(\mathrm{X}_{4} \mathrm{G}_{4}\right)_{6} \mathrm{X}$ \\
16 & $\mathrm{G}\left(\mathrm{X}_{8} \mathrm{G}_{8}\right)_{3} \mathrm{X}$ \\
\hline
\end{tabular}

Poly $(L$-lysine trifluoroacetate or bromide $)$ and $\operatorname{poly}(D, L$-glutamate sodium salt $)$ with chain lengths of $\mathrm{N}=100,400$, and 800 were purchased from Alamanda Polymers and used without further purification. These polymers were synthesized via N-carboxyanhydride polymerization using an alkylamine initiator. ${ }^{133}$ The degree of polymerization was reported by the manufacturer based on ${ }^{1} \mathrm{H}$ NMR analysis with a polydispersity index (PDI) between 1.01 and 1.08 for all $\mathrm{N}=100,400$, and 800 polymers (Table S2). Table S2 also includes mean squared radius of gyration estimations assuming ideal flexible chain behavior.

\section{Coacervate Preparation:}

Polypeptide stock solutions were prepared gravimetrically using Milli-Q water at a concentration based on the total number of amino acids present. For instance, a stock solution of poly(glutamate) of $10 \mathrm{mM}$ amino acid would be used in parallel with a stock solution of the poly(lysine-co-glycine), also at $10 \mathrm{mM}$ with respect to the total number of amino acids, or $5 \mathrm{mM}$ with respect to the number of charged monomers present in solution. All solutions were adjusted to $\mathrm{pH}=7.0 \pm 0.03$ using concentrated solutions of $\mathrm{HCl}$ and $\mathrm{NaOH}$, as needed. Monomer concentration was chosen as the experimental basis in order to easily enable direct stoichiometric comparison of the number of positively and negatively charged units present in solution.

Complexation was achieved by mixing aqueous solutions of cationic poly(lysine)-based peptides with anionic poly(glutamate)-based peptides, potentially in the presence of buffer and/or additional salt. Samples were prepared using a Biomek $\mathrm{NX}^{\mathrm{P}}$ (Beckman Coulter) liquid handling 
robot. Water, followed by concentrated solutions of buffer and salt, as needed, were pipetted into a Falcon flat bottom 384-well plate (Fisher Scientific). The first polypeptide was added and the solution was then mixed using an orbital shaker for $15 \mathrm{~s}$, after which the second polypeptide was added to a final sample volume of $35 \mu \mathrm{L}$ per well. The final sample was mixed again for $30 \mathrm{~s}$ using the orbital shaker. All samples were prepared in triplicate.

For experiments intended to investigate the kinetics of coacervate assembly, the small volume and rounded square shape of the wells in a 384-well plate did not allow for effective mixing, allowing us to monitor the samples as they reach equilibrium. However, preparation of samples in a larger volume, such as a 96-well plate with a total sample volume of $150 \mu \mathrm{L}$ per well, did allow for fast mixing and samples could be moved from the 96-well plate to the 384-well plate fully equilibrated.

Complexation was performed over a range of different ratios of positive and negatively charged polypeptides at a total monomer concentration of $2 \mathrm{mM}$, at $\mathrm{pH} 7.0$. Under these conditions, it is a reasonable approximation to describe both lysine and glutamate as fully charged. Two experiments were run simultaneously to test the order of the addition for the polypeptides; one where the polyanion was pipetted into the well plate first and another where the polycation was added first. Each experiment was performed at sixteen different charge fractions, although the selection of data points to be sampled was skewed in favor of net negative or net positive conditions, based on the order of peptide addition. Immediately following sample preparation, the well plate was transferred to the plate reader for analysis.

Two control experiments were performed to establish how mixing affects our experimental results. The first, well-mixed experiment was prepared by hand, at a total sample volume of 120 $\mu \mathrm{L}$ per tube, using $(\mathrm{EG})_{25} /(\mathrm{KG})_{25}$ where the same procedure as described above was followed, pipetting solutions into $1.5 \mathrm{~mL}$ Eppendorf tubes and vortexing for approximately $5 \mathrm{~s}$ after the addition of each solution. Three $35 \mu \mathrm{L}$ aliquots were then transferred to a 384-well plate for each sample. The plate was read immediately after making the samples and pipetting them into the plate. The goal of the second control experiment was to test the effect of the orbital shaker on the Biomek liquid handling robot. This experiment used same system of $(\mathrm{EG})_{25} /(\mathrm{KG})_{25}$, and samples were prepared using the Biomek. The same procedure was used, but the mixing steps were removed.

\section{Turbidity Analysis:}

A plate reader equipped with a UV spectrophotometer (Synergy H1, BioTek, Inc.) was used to measure changes in the turbidity at a wavelength of $562 \mathrm{~nm}$ as a function of time. None of the polymers absorb light at this wavelength; thus, turbidity is due to light scattering from suspended coacervate droplets. Turbidity is defined by $-\ln \left(I / I_{0}\right)$, with $I_{0}=$ incident light intensity and $I=$ intensity of light passed through the sample volume.

Static turbidity measurements were used for characterization of well-mixed samples, followed by examination of samples via optical microscopy (EVOS XL Core, Fisher Scientific) to confirm coacervate formation. These samples were imaged directly after preparation.

For time-resolved experiments, turbidity data were collected every 5 min for 90 min, unless otherwise noted. For the control experiment, where no plate mixing steps were performed during 
sample preparation, turbidity measurements were taken every 5 min for $6 \mathrm{~h}$.

\section{Data Analysis:}

MATLAB (The Mathworks Inc.) scripts were written to fit a Gaussian unimodal curve to describe the stoichiometric curve at each time point. These curves were then used to track shifts in the observed phase behavior as a function of time. The Gaussian is described as:

$$
G=A e^{-\frac{(x-b)^{2}}{2 c^{2}}}
$$

$A$ is the height of the peak, $b$ is the position of the center of the peak, $c$ is the standard deviation of the curve, and $x$ is the independent variable, which is the charge fraction. The code found the maximum turbidity, the position of this maximum, and the standard deviation of the all the turbidities at each time point and used these as initial guesses for $A, b$, and $c$, respectively. The built-in MATLAB function nlinfit was then utilized to find the best parameters for each Gaussian time set. The full MATLAB code is available in the Supplementary Information.

Using the peak locations from the Gaussian models, a peak location versus time curve was constructed along with confidence intervals for the peak location based on the variation in the raw data. We defined the time to reach equilibrium as the time point at which the peak location first reached its maximum or minimum, depending on the order of addition. In addition to this elapsed time calculation, we also evaluated our data by determining the "half-time," or the time required to reach half of the maximum or minimum value. Details on this method are described in the Supplementary Information and all elapsed times and half-times are outlined in Table S1.

\section{Results and Discussion:}

The goal of these experiments was to understand the formation and equilibration aspects of complex coacervates using small volumes of material. This approach has the benefit of being accessible to a wide range of scientists, and also has the potential to provide insight into the formulation requirements of coacervate materials.

\section{Coacervation by Hand and by Machine:}

When two oppositely charged polyelectrolytes are brought together to form a complex coacervate, maximum complex formation is typically observed under conditions of charge neutrality. Thus, if the two polyelectrolytes are of equal length and charge density, net neutrality and the maximum level of complexation is expected to occur with equal numbers of each polyelectrolyte. These trends as a function of the charge stoichiometry of the system are easily observed through the use of turbidimetry. Samples for such experiments are typically prepared using a pipette, microcentrifuge tubes, and a vortex mixer, and a key aspect of any protocol is ensuring that the samples are fully equilibrated. The equilibrium nature of complex coacervation is often determined by testing whether or not changing the order of addition of the components affects the results. ${ }^{21,131,134,135}$ An example of results from a well-mixed, fully-equilibrated turbidity experiment for the oppositely-charged polypeptides of poly(lysine-co-glycine) and poly(glutamate-co-glycine) is shown in Figure 1 (black curve), and previous reports of polypeptide-based complex coacervation, as well as our own experience, have suggested that the hydrophilic nature of these peptide-based materials allows for easy sample preparation and equilibration. $6,8,10,13,16,17,20,48,131,135-137$ 


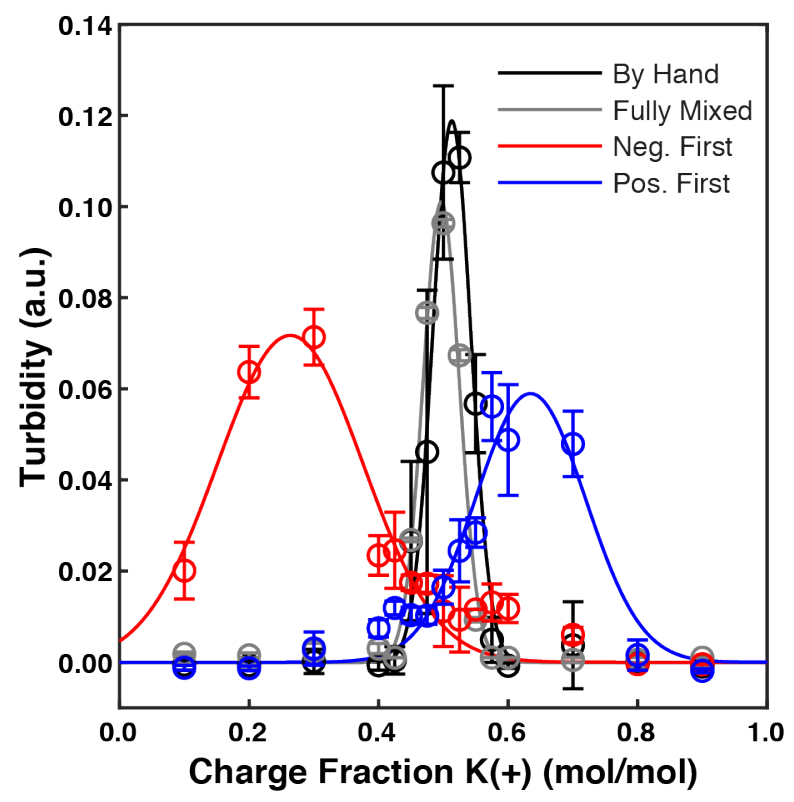

Figure 1. Stoichiometry experiment showing turbidity as a function of the mole fraction of cationic monomer present for coacervates of $(\mathrm{EG})_{25} /(\mathrm{KG})_{25}$ prepared "by hand" pipetting and vortexing (black), as "fully mixed" samples prepared by the liquid handling robot using a 96-well plate, followed by aliquoting into a 384-well plate for analysis (grey), and poorly mixed samples prepared by the liquid handling robot directly into a 384-well plate named "Neg. First" with the negative polyelectrolyte added first (red) or "Pos. First" with the positive polyelectrolyte added first (blue). Error bars represent the standard deviation of $\mathrm{N}=27$.

While the preparation of samples by hand allows for excellent control over sample mixing, the need to survey a broad range of formulation conditions often calls for scaling down and automation of the experiments. To this end, we decreased the scale of our experiments from a total volume of $120 \mu \mathrm{L}$ prepared by hand in a single microcentrifuge tube and aliquoted into a 384-well plate, to direct preparation of $35 \mu \mathrm{L}$-scale samples in the well plate using a liquid handling robot. However, we were surprised to discover that the results from a standard stoichiometry experiment did not match those that we regularly obtained by hand. Rather than observing a peak at the charge-neutral mole fraction of 0.5 , our maximum was shifted to lower cationic charge fractions (Figure 1, red curve).

Our standard protocol for preparing coacervate samples involved the mixing of water, followed by buffer/salt (as needed), and then the polyanion followed by the polycation. However, given the surprising result that we had obtained with our first experiment, we then ran a test with the polycation added first. Interestingly, whereas the experiment with the polyanion added first showed a peak in the turbidity at net negative mole fractions, our "polycation first" experiments showed a peak in the turbidity at net positive mole fractions (Figure 1, blue curve). Subsequent tests demonstrated that we could eliminate this phenomenon by preparing samples in a larger, 96-well plate, followed by aliquoting into the 384-well plate for analysis (Figure 1, grey curve).

The different turbidity results obtained from the direct preparation of samples into the small well (roughly $3 \mathrm{~mm}$ by $3 \mathrm{~mm}$ square) of a 384-well plate compared with those of a 96-well plate ( $\sim 6.35 \mathrm{~mm}$ diameter circle) suggested that the size of the different wells might be directly affecting the ability of the polymers to mix. Quick calculations using the well plate dimensions and an orbital mixing speed of $950 \mathrm{rpm}$ allow us to estimate the Reynolds number (i.e., the ratio 
of inertial to viscous forces) for water at $25^{\circ} \mathrm{C}$ in the 384 -well plate as $\operatorname{Re} \sim 546$, whereas for the larger 96-well plate $\operatorname{Re} \sim 2,247$. These results suggest that flow in the 384-well plate is laminar (i.e., $\operatorname{Re}<2,200$ ), while the 96-well plate experiences transitional flow (i.e., 4,000 > $\operatorname{Re}>2,200$ ). Furthermore, we estimated the timescale for purely diffusive mixing for the polymer to move halfway across the well as $\sim 3.4 \mathrm{hr}$ and $\sim 14.0 \mathrm{hr}$ for the 384- and 96-well plates, respectively. Thus, the enhancement of the more chaotic flow allows for better mixing in the 96-well plate versus the purely laminar flow in the 384-well plate. Details of the calculations are available in the Supplementary Information.

While we were able to develop protocols that allowed us to operate our liquid handling robot in a manner such that we could reproduce results obtained by hand, we were also interested in further exploring the observation that poor mixing could lead to differences in the observed outcome. To this end, we used the liquid handling robot to directly prepare "poorly mixed" samples in 384well plates, and used a plate reader to track changes in the turbidity signal as a function of time. These first experiments involved sequence-controlled polypeptides that were symmetric to each other with respect to charge pattern; a polyanion with an alternating sequence of one neutral monomer and one negatively charged monomer would be paired with a polycation with the equivalent charge pattern (i.e., $(\mathrm{EG})_{25} /(\mathrm{KG})_{25}$ using the single letter notation for amino acids). As in Figure 1, when the positively charged polypeptide was added first, the turbidity signal was first observed to the right of net neutrality, at "net positive" conditions. Over the course of 90 minutes, the turbidity signal shifted back to equilibrate around net neutral conditions (Figure 2a). The opposite trend was observed when the polyanion was added first, showing an initial turbidity signal at "net negative" conditions that shifted up to net neutrality (Figure 2c). It is interesting to note that the symmetry in the structure and charge density of the peptides is matched by the symmetry in timescales for equilibration. Similarly symmetric results were seen for matched pairs of polypeptides including homopolymers (Figures S1 and S2) and those with different charge block sizes (Figures S3 and S4), suggesting that this is a general phenomenon.

We determined a characteristic time for equilibration by first fitting the raw turbidity data at each time point using a Gaussian peak. This peak location data could then be plotted as a function of time (Figure 2b,d). We then chose to characterize the equilibration time for our system as the time at which the turbidity signal first reached its final peak location (i.e., elapsed time, Figure $2 \mathrm{~b}, \mathrm{~d}$ black squares). It was also possible to determine a characteristic half-time for equilibration (Figure 2b,d black diamonds). However, the time needed to transport the samples between the liquid handling robot and the plate reader made collection of data at very short timescales difficult. Thus, while similar trends were observed when using half-times, we have elected to utilize the "elapsed" timescale as our characteristic measure. We also note that there was a slight difference in the preparation and readout timescale between samples where the negative polyelectrolyte added first and the positive polyelectrolyte added first due to the sequential way in which the samples were prepared and the turbidity was read. Both directions were done together in one experiment, with samples where the polyanion was added first prepared and measured before those where the polycation was added first. We estimate that this difference is less than $1 \mathrm{~min}$. To account for this, the average between the two times were used. 

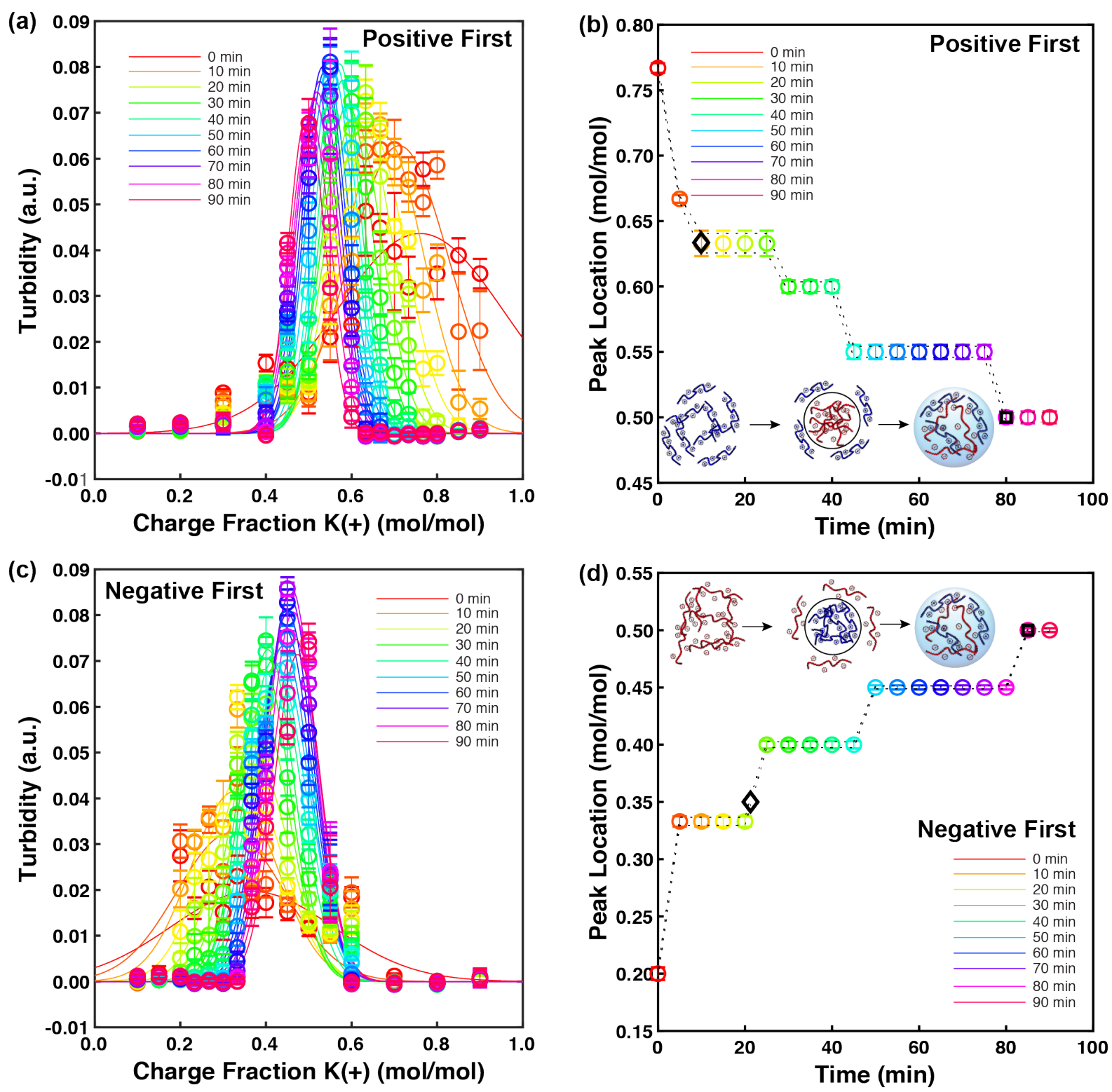

Figure 2. Plots of the evolution of turbidity as a function of the cationic charge fraction and time for the complexation of $(\mathrm{EG})_{25} /(\mathrm{KG})_{25}$ at $\mathrm{pH} 7.0$ in water for samples where the (a) concentrated (EG) $)_{25}$ was mixed into dilute (KG) ${ }_{25}$, ("positive first") and the opposite case (c) where the concentrated $(\mathrm{KG})_{25}$ was added into dilute $(\mathrm{EG})_{25}$ ("negative first"). Plots of peak location versus time for (b) $(\mathrm{KG})_{25}$ added first and (d) $(\mathrm{EG})_{25}$ added first. Schematic representations of the mixing conditions are shown in (b) and (d). Black symbols indicate the characteristic times for sample equilibration, with diamonds marking the half times and black squares marking the elapsed time. Elapsed times for (a) and (b) are $80 \mathrm{~min}$ and $85 \mathrm{~min}$, respectively. Error bars represent the standard deviation of $\mathrm{N}=27$.

\section{Exploring the Effect of Sequence in the Presence of Buffer:}

Inspired by the results shown in Figure 2, we decided to expand our study to include a broader set of peptides. We also decided to buffer our system with a zwitterionic (net neutral) buffer, HEPES, to better maintain a constant $\mathrm{pH}$ of 7.0. Initial experiments had demonstrated that the addition of $10 \mathrm{mM}$ HEPES did not have a significant effect on the turbidity signal observed during a stoichiometry experiment, and only a small effect on the phase behavior of our coacervates, reducing the salt resistance of the resulting coacervate slightly, but less than the 
addition of an equivalent concentration of another salt (see Figure S5).

\section{Symmetry in Polypeptides:}

To begin with, we repeated the experiment with $(\mathrm{EG})_{25} /(\mathrm{KG})_{25}$ shown in Figure 2, this time with the addition of buffer. Interestingly, we observed that the addition of $10 \mathrm{mM}$ HEPES as a neutral, zwitterionic buffer resulted in a smaller offset for the initial turbidity signal from net neutrality (Figure 3). While the trends are the same for both directions, the first peak in the positive first data at $\mathrm{t}=0$ without buffer was observed at 0.760 , while the one with buffer occurred at 0.530 Similarly, for the negative first experiment the first peak without buffer was observed at 0.367 while the one with buffer occurred at 0.415 . In addition to and consistent with a decrease in the observed initial offset in our turbidity data, the addition of buffer also served to accelerate the overall time for equilibration. In the absence of buffer, the average elapsed time for equilibration was $82.5 \mathrm{~min}$, whereas with buffer it decreased to $50.0 \mathrm{~min}$. This dramatic acceleration (a roughly $\sim 40 \%$ decrease in elapsed time) was unexpected given the fact that the $\sim 86 \%$ of the salt resistance was retained with the addition of $10 \mathrm{mM}$ of HEPES buffer. Further studies looking into the rheological effects of small molecules such as the zwitterionic HEPES buffer would help to elucidate this trend, but are beyond the scope of the current work. 

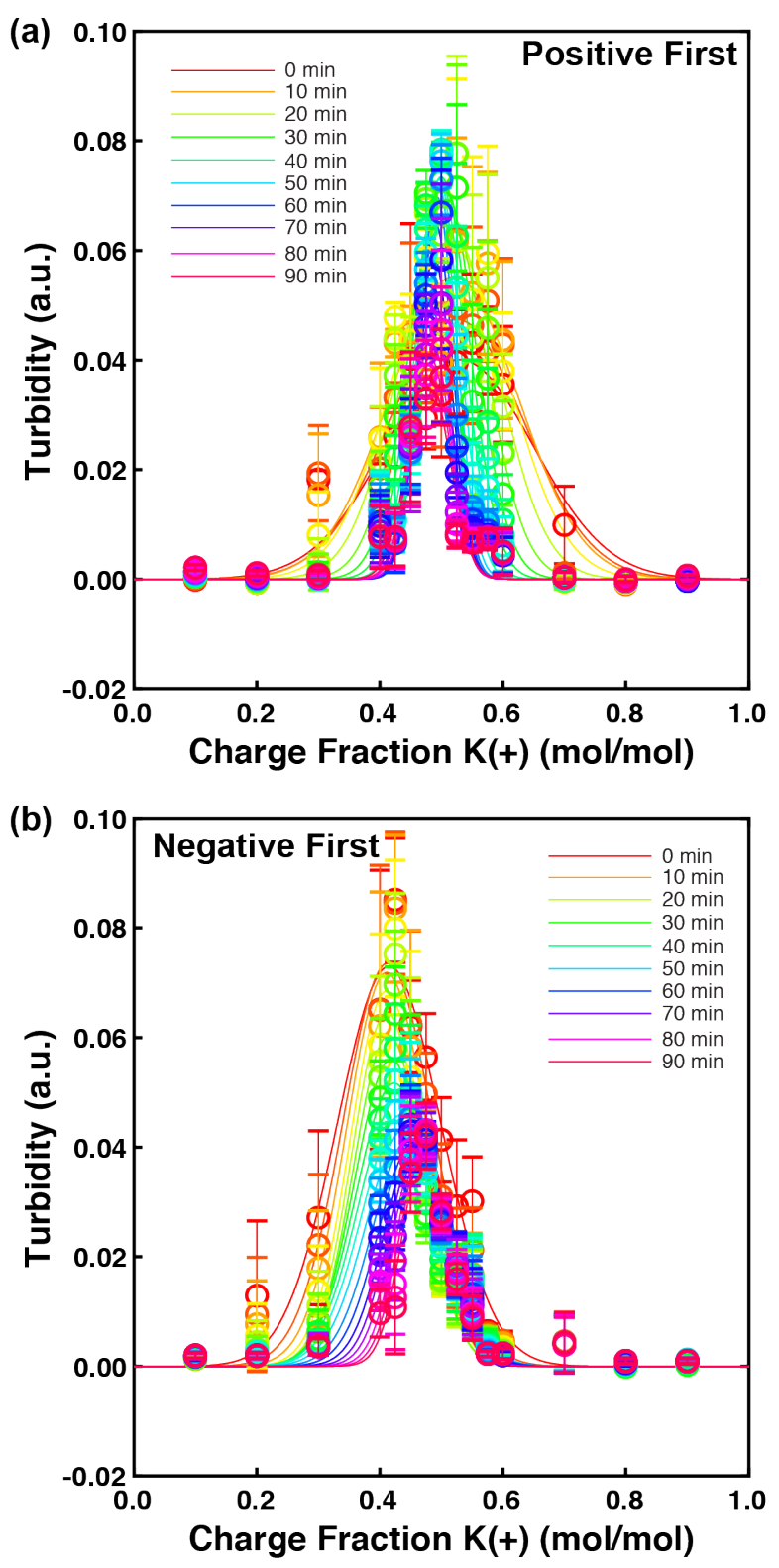

Figure 3. Plots of the evolution of turbidity as a function of the cationic charge fraction and time for the complexation of $(\mathrm{EG})_{25} /(\mathrm{KG})_{25}$ at $\mathrm{pH} 7.0$ in water for samples where the (a) concentrated (EG) $)_{25}$ was mixed into dilute (KG) ${ }_{25}$, ("positive first") and the opposite case (c) where the concentrated $(\mathrm{KG})_{25}$ was added into dilute (EG) ${ }_{25}$ ("negative first") in 10 mM HEPES buffer. The elapsed time for sample equilibration was determined to be $30 \mathrm{~min}$ for (a) and $70 \mathrm{~min}$ for (b). Error bars represent the standard deviation of $\mathrm{N}=27$.

\section{Asymmetry in Polypeptides:}

After investigating complexation between polypeptides with the same sequence and charge density, we then moved on to consider two polypeptides that were not symmetrical to each other. In particular, we substituted one of the peptides from our previous system with the fully-charged homopolymer (i.e., $(\mathrm{KG})_{25} / \mathrm{E}_{50}$ and $\mathrm{K}_{50} /(\mathrm{EG})_{25}$ ). 
No Buffer
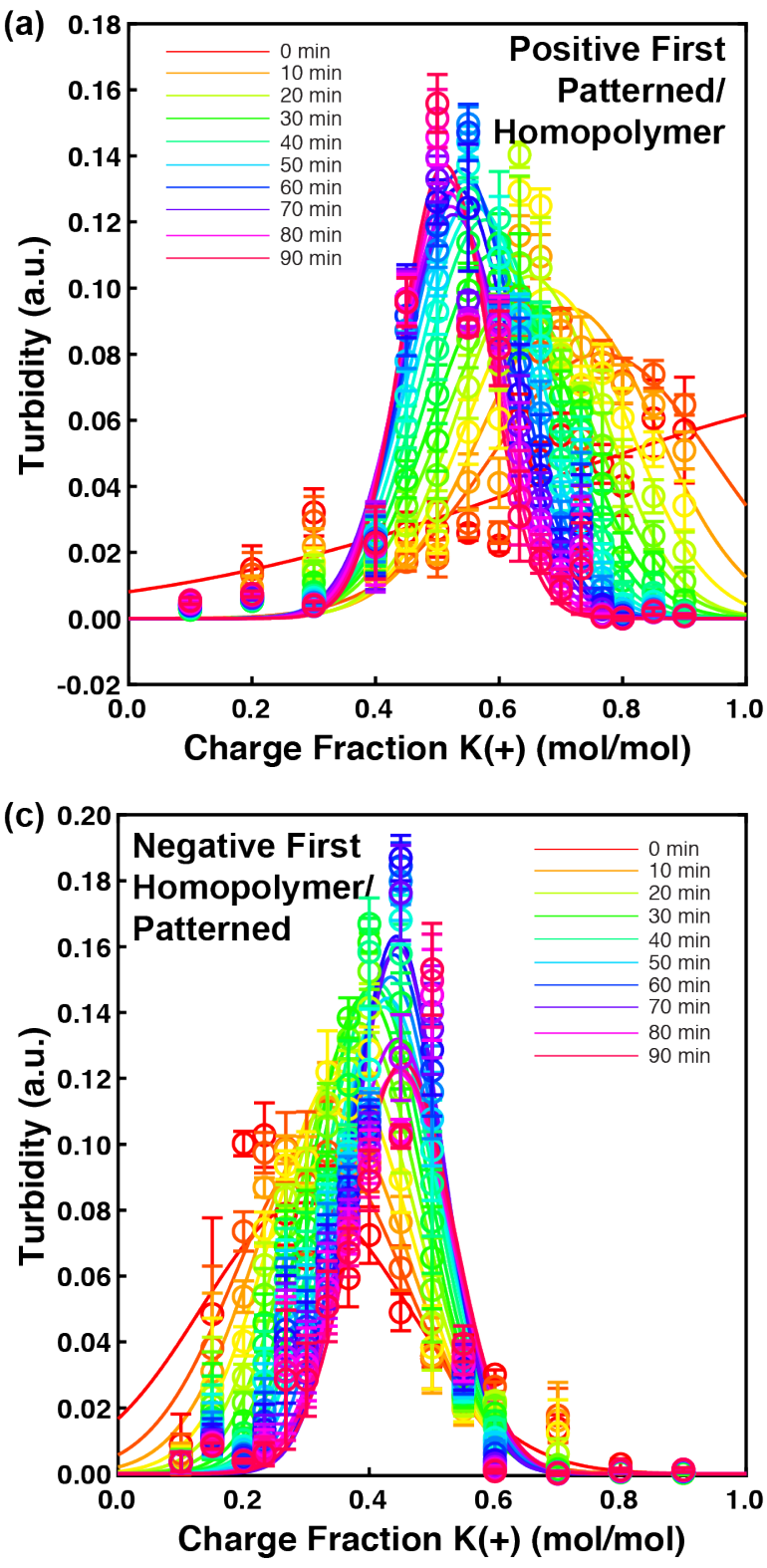

\section{$10 \mathrm{mM}$ HEPES}
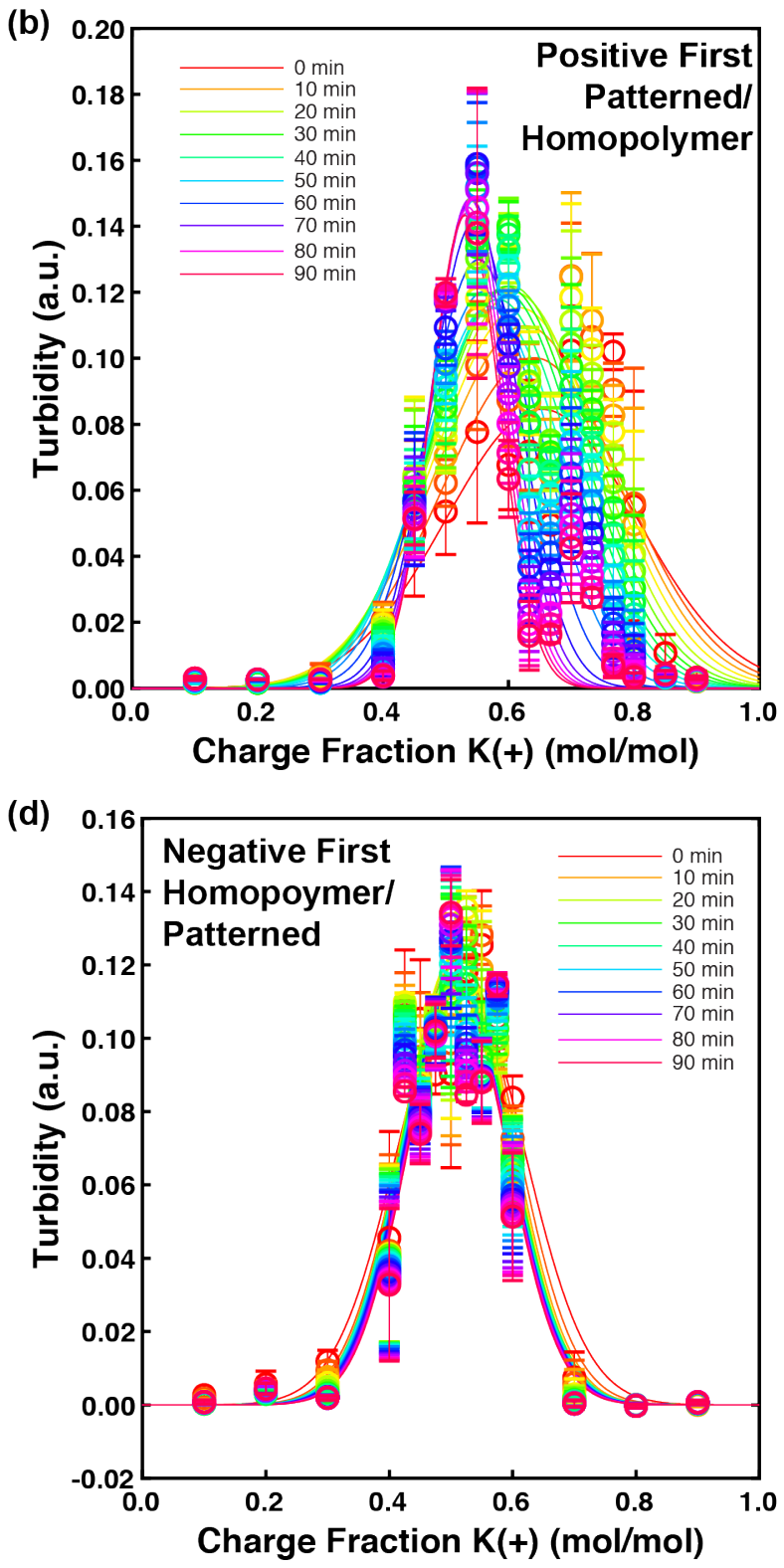

Figure 4. Plots of the evolution of turbidity as a function of the cationic charge fraction and time for the complexation of $\mathrm{E}_{50}$ and $(\mathrm{KG})_{25}$. (a) Shows the addition of $(\mathrm{KG})_{25}$ first and (c) shows the addition of $E_{50}$ first. (b) Shows the addition of (KG) $)_{25}$ first and (d) shows the addition of $\mathrm{E}_{50}$ first in the presence of $10 \mathrm{mM}$ HEPES. When the patterned polyelectrolyte was added first in the presence of buffer, there is an initial offset followed by a shift toward equilibrium, whereas there is little to no offset observed when the homopolymer is added first. Elapsed time is (a) $65 \mathrm{~min}$ and (c) $75 \mathrm{~min}$ with no buffer and (b) $85 \mathrm{~min}$ and (d) $15 \mathrm{~min}$ in the presence of $10 \mathrm{mM}$ HEPES. Error bars represent the standard deviation of $\mathrm{N}=27$.

Replacing a half-charged peptide with a fully-charged homopolymer of the same overall length represented the most drastic change that we could make in our materials while keeping chain length constant. While our previous results had shown relatively symmetric behavior with respect to the order of addition, for these mismatched, or asymmetric polypeptide systems we observed a significant difference in the equilibration behavior depending on which polymer was added first. In our $\mathrm{pH}$ buffered system, the addition of the patterned polypeptide first showed 
results that were similar, though slightly faster, to those observed previously for the unbuffered system (Figure 4a,b). However, when the homopolymer was added first, the turbidity signal equilibrated to the expected conditions around net neutrality almost immediately when buffer was present (Figure 4d). Similar trends were observed for other peptide systems, regardless of the identity of the patterned/homopolypeptides (see Figure S6). However, in the absence of buffer, we do not see the almost instantaneous equilibration with the addition of the homopolymer added first (Figure 4c). These data suggest that presence or absence of even a zwitterionic buffer is a means by which the equilibration time can be tuned, and that this particular phenomenon may be very sensitive to the density of charges present on the polymers. Further exploration of this potential phenomenon, as well as a more in depth exploration of sequence on the rates of equilibration is an interesting area for future study. In particular, the dramatic effects of charge patterning mismatch could have significant implications when applied to industrial-scale formulation.

\section{Is This Just Diffusion? Chain Length of Polypeptides:}

An obvious question related to the varying results presented thus far is whether the observed differences are evidence of anything other than diffusion. For symmetric peptide systems, the molecular weights of the lysine and glutamate copolymers are similar, and thus symmetric trends in the data would not be unreasonable. Additionally, the addition of buffer seems to act like a salt, though to a lesser extent, because of its zwitterionic nature. However, our observations for asymmetric coacervate systems (Figures 4, S6-S8) suggest that forces beyond simple diffusion are at play.

To test whether or not the temporal changes in the turbidity results were caused by merely diffusion, we first examined the effect of polymer chain length. If diffusive effects were the dominant factor in our experimental observations, we would expect to observe an increase in the elapsed time for equilibration with increasing polypeptide chain length. We tested coacervation between $K_{N}$ and $E_{N}$ with degree of polymerization $N=50,100,400$, and 800 . These experiments were performed in the absence of buffer so as to slow down the timescales for equilibration and allow for clear differentiation of the different polymer systems.

Our experimental results showed a non-monotonic dependence on chain length, with a maximum equilibration time observed with $\mathrm{N}=100$, followed by a subsequent decrease in the equilibration time with increasing chain length (Figure 5). Diffusivity is expected to scale as $\sim \mathrm{N}$. ${ }^{138}$ However, in order to observe the "volcano" type of trend with increasing chain length, there must be another factor that accelerates motion with increasing chain length. While a detailed exploration of this phenomenon is beyond the scope of the current publication, we hypothesize that factors such as excluded volume effects analogous to those observed in size exclusion chromatography, exchange dynamics within a polyelectrolyte complex, as well as differences in the driving force for complexation may play a role. Thus, both the length and the charge density of the polymers appear to play a significant role in determining the timescale for a coacervating system to equilibrate. 


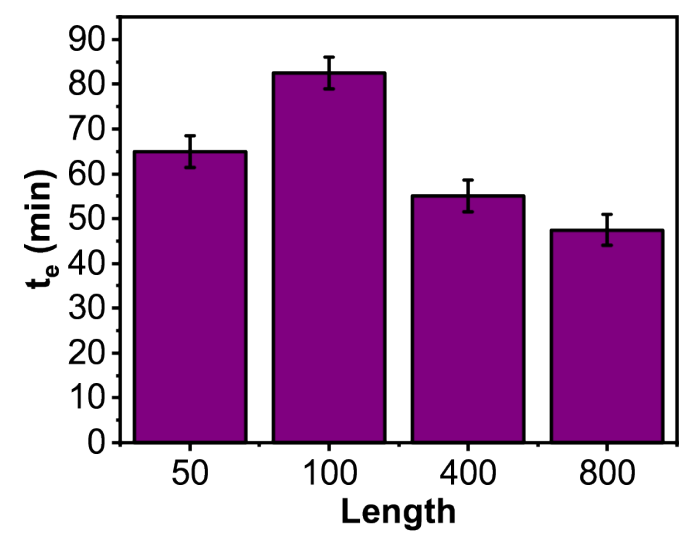

Figure 5. Average elapsed for the equilibration of $K_{N}$ and $E_{N}$ as a function of polypeptide lengths $N=50,100,400$, and 800 with no buffer present. Error bars represent the propagated error.

\section{Effect of Salt:}

The combination of results presented thus far suggested that the differences in equilibration time for our poorly mixed turbidimetry experiments could provide insight into the strength of interactions between polymer species in our coacervate materials, somewhat analogous to either a viscosity or a stress relaxation measurement. The addition of salt has long been used as a way of modulating the rheological properties of complex coacervates and polyelectrolyte complexes generally. ${ }^{13,137,139-144}$ Thus, we investigated the effect of added salt and salt identity on coacervate equilibration.

To begin with, we tested the effect of increasing salt concentration. In Figure 6a, we compare the elapsed time for complexation between $(\mathrm{EG})_{25}$ and $(\mathrm{KG})_{25}$ in the absence of added salt, as well as the addition of $10 \mathrm{mM}$ and $25 \mathrm{mM} \mathrm{KBr}$. The addition of even a small amount of salt has a tremendous effect on the time needed for sample equilibration, with the average elapsed time decreasing from $82.5 \mathrm{~min}$ to $5.0 \mathrm{~min}$ with the addition of only $10 \mathrm{mM} \mathrm{KBr}$. With the addition of higher salt concentrations, the calculated elapsed time decreased further, and it became difficult to accurately determine a time scale.

Our results correlate with reports from the literature that salt accelerates both the kinetics of coacervate formation and the timescale for relaxation. Liu et al. used stopped-flow light scattering to study the kinetics of coacervation upon fast mixing of two oppositely-charged polymers. ${ }^{126,127}$ The time scale for complexation decreased with the increasing addition of salt, similar to trends found with our data. ${ }^{127}$ A report by Salehi et al., on the layer-by-layer assembly of polyelectrolytes, illustrated an optimum range of salt between $15-60 \%$ of the maximum salt concentration where complexation can occur where there is a faster growth. ${ }^{121}$ However, this report, and other reports, focused solely on one type of salt with different systems, making it difficult to draw conclusions of how the type of salt affects the kinetics. ${ }^{119,121}$ Further exploration and comparison of different salts could help elucidate the effects of salt composition on the kinetics of polyelectrolyte complexation. These parallel results with respect to salt are in contrast to the absence of reports on other parameters such as chain length and charge density/patterning, for which, to the best of our knowledge, there has been little to no study on.

Rheological measurements have also highlighted the dramatic effect that increasing salt concentrations can have on the viscosity and/or relaxation behavior of complex 
coacervates. $^{111,137,139-143,145}$ This salt effect has been described in terms of the ability of salt to lower the activation energy barrier for the rearrangement of ion pairs using a "sticky" Rouse model. ${ }^{141,142}$ The specific chemical identity of the salt ions has also been shown to have a significant effect on both the phase behavior and the rheology of coacervates. ${ }^{8,145}$ These effects have largely been associated with Hofmeister-like effects that can be attributed to the ability of the various ions to affect the structure of water. ${ }^{146-150}$

We compared the effect of both the cation and the anion by testing a series of alkali halide salts at $10 \mathrm{mM}$ concentration with the system of $(\mathrm{EG})_{25}$ and $(\mathrm{KG})_{25}$. By merely changing the identity of the salt ions we observed a dramatic acceleration in the time needed for our samples to equilibrate. $\mathrm{KBr}$ had the fastest average elapsed time of $5.0 \mathrm{~min}$, followed by $35.0 \mathrm{~min}$ for $\mathrm{NaBr}$, 57.5 min for $\mathrm{KCl}$, and $\mathrm{NaCl}$ at 62.5 min (Figure 6b). Interestingly, the result for $\mathrm{NaCl}$ was comparable to what was seen with no added salt (Figures 5, S9d, and S10d).
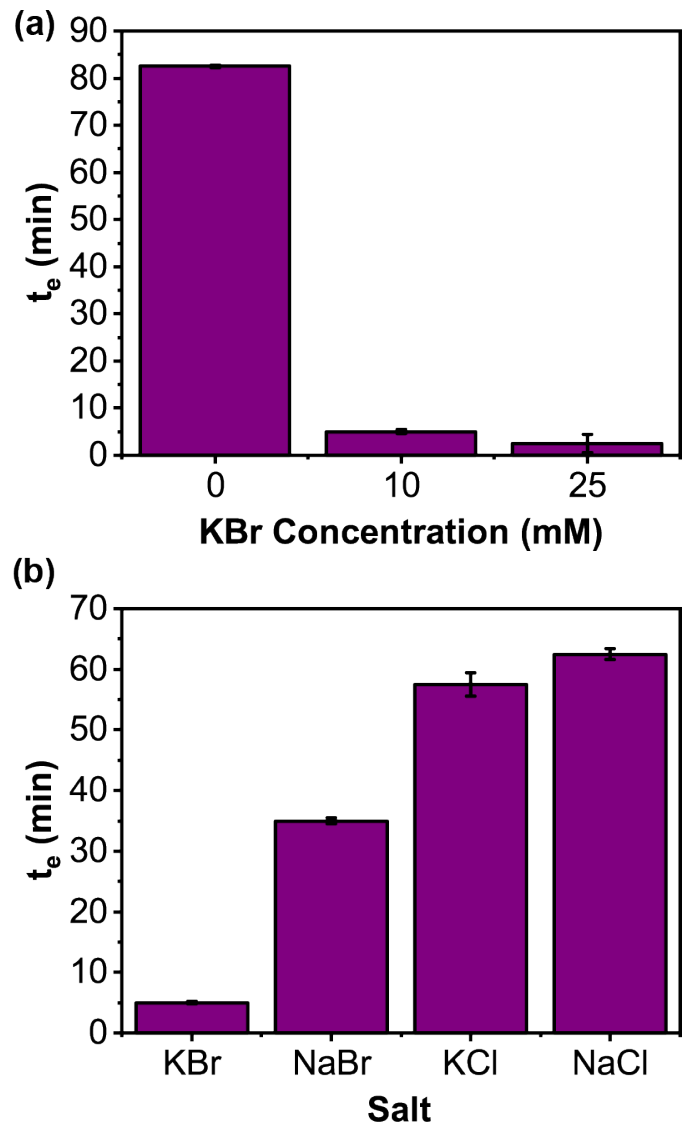

Figure 6. (a) The effect of increasing salt concentration with $\mathrm{KBr}$ on the average elapsed time of $(\mathrm{EG})_{25} /(\mathrm{KG})_{25}$, and (b) the effect of varying alkali halide salts at $10 \mathrm{mM}$ and using the same system. Error bars represent the propagated error.

Our trends parallel rheological data reported by Sadman et al., who used quartz crystal microbalance (QCM) studies to characterize thin films of poly(4-styrenesulfonic acid, sodium salt) (PSS) and poly(diallyldimethyl ammonium chloride) (PDADMAC). ${ }^{145}$ The QCM data showed that the salt-induced changes in the modulus of the films correlated with the ability of the individual salts to bring water into the film. These results are particularly interesting as the trends of $\left(\mathrm{Br}^{-}<\mathrm{Cl}^{-}\right.$and $\left.\mathrm{K}^{+}<\mathrm{Na}^{+}\right)$and those from Sadman et al., correlate with a decrease in the 
hydration of the ions while resulting in an overall increase in the amount of water brought into the coacervate. More work is needed to better understand this phenomenon.

\section{Conclusions:}

We developed a turbidimetric method that uses small volumes and poor mixing to track the equilibration of a panel of complex coacervate samples prepared across a range of charge stoichiometries. Whereas a "well-mixed" experiment would be expected to result in a turbidity signal that is peaked at a 1:1 charge stoichiometry, corresponding to net neutrality, we saw a shift in the turbidity signal to net negative or net positive stoichiometries, depending on the order of polymer addition. The location of this peak could then be tracked over time as it shifted towards the expected 1:1 stoichiometry to identify a characteristic time scale for equilibration.

Analysis of the equilibration time for coacervates formed from polymers with increasing chain length demonstrated the ability of this method to probe both diffusion and frictional effects associated with the electrostatic interactions driving coacervation. The addition of salt or a zwitterionic buffer served to decrease the inter-chain friction, accelerating equilibration. Interestingly, we observed marked differences in the frictional interactions between polypeptides with asymmetric patterns of charge, depending on the order of polymer addition.

This method has the potential to provide insight into differences in the associative interactions present in different coacervate formulations. While not a replacement for more advanced techniques such as rheology that can more accurately and quantitatively probe the internal structure and dynamics of a material, the ability to perform simple characterizations with extremely low sample requirements in parallel with ongoing turbidimetric studies could help to serve as a screening tool to identify interesting and unique phenomena for further study.

\section{Acknowledgements:}

W.C.B.M. was supported by a Fellowship from the Soft Materials for Life Sciences National Research Traineeship Program \#NRT-1545399. The authors would also like to thank Prof. Charles E. Sing, Prof. David Hoagland, Dr. Matthew Langer, and Xianci Zeng for helpful discussions. 


\section{References:}

(1) Sing, C. E.; Perry, S. L. Recent progress in the science of complex coacervation. Soft Matter 2020, 50, 9528-9530 DOI: 10.1039/D0SM00001A.

(2) Blocher McTigue, W. C.; Perry, S. L. Protein Encapsulation Using Complex Coacervates: What Nature Has to Teach Us. Small 2020, 111, e1907671 DOI: 10.1002/smll.201907671.

(3) Timilsena, Y. P.; Akanbi, T. O.; Khalid, N.; Adhikari, B.; Barrow, C. J. Complex coacervation: Principles, mechanisms and applications in microencapsulation. Int. J. Biol. Macromol. 2019, 121 (C), 1276-1286 DOI: 10.1016/j.ijbiomac.2018.10.144.

(4) Eratte, D.; Dowling, K.; Barrow, C. J.; Adhikari, B. Recent advances in the microencapsulation of omega-3 oil and probiotic bacteria through complex coacervation A review. Trends Food Sci Technol 2018, 71, 121-131 DOI: 10.1016/j.tifs.2017.10.014.

(5) Pathak, J.; Priyadarshini, E.; Rawat, K.; Bohidar, H. B. Complex coacervation in charge complementary biopolymers: Electrostatic versus surface patch binding. Adv. Colloid Interface Sci. 2017, 250 (C), 40-53 DOI: 10.1016/j.cis.2017.10.006.

(6) Blocher, W. C.; Perry, S. L. Complex coacervate-based materials for biomedicine. WIREs Nanomed Nanobiotechnol 2017, 9, e1442 DOI: 10.1002/wnan.1442.

(7) Veis, A. A review of the early development of the thermodynamics of the complex coacervation phase separation. Adv. Colloid Interface Sci. 2011, 167, 2-11 DOI: 10.1016/j.cis.2011.01.007.

(8) Perry, S.; Li, Y.; Priftis, D.; Leon, L.; Tirrell, M. The effect of salt on the complex coacervation of vinyl polyelectrolytes. Polymers 2014, 6 (6), 1756-1772 DOI: 10.3390/polym6061756.

(9) Priftis, D.; Leon, L.; Song, Z.; Perry, S. L.; Margossian, K. O.; Tropnikova, A.; Cheng, J.; Tirrell, M. Self-assembly of $\alpha$-helical polypeptides driven by complex coacervation. Angew. Chem. 2015, 127 (38), 11280-11284 DOI: 10.1002/ange.201504861.

(10) Hoffmann, K. Q.; Perry, S. L.; Leon, L.; Priftis, D.; Tirrell, M.; de Pablo, J. J. A molecular view of the role of chirality in charge-driven polypeptide complexation. Soft Matter 2015, 11 (8), 1525-1538 DOI: 10.1039/C4SM02336F.

(11) Water, J. J.; Schack, M. M.; Velazquez-Campoy, A.; Maltesen, M. J.; van de Weert, M.; Jorgensen, L. Complex coacervates of hyaluronic acid and lysozyme: Effect on protein structure and physical stability. 2014, 88 (2), 325-331 DOI: 10.1016/j.ejpb.2014.09.001.

(12) Black, K. A.; Priftis, D.; Perry, S. L.; Yip, J.; Byun, W. Y.; Tirrell, M. Protein encapsulation via polypeptide complex coacervation. ACS Macro Lett. 2014, 3 (10), 1088-1091 DOI: $10.1021 / \mathrm{mz} 500529 \mathrm{v}$.

(13) Perry, S. L.; Leon, L.; Hoffmann, K. Q.; Kade, M. J.; Priftis, D.; Black, K. A.; Wong, D.; Klein, R. A.; Pierce, C. F.; Margossian, K. O.; et al. Chirality-selected phase behaviour in ionic polypeptide complexes. Nat Commun 2015, 6 (1), 6052 DOI: 10.1038/ncomms7052.

(14) Priftis, D.; Xia, X.; Margossian, K. O.; Perry, S. L.; Leon, L.; Qin, J.; de Pablo, J. J.; Tirrell, M. Ternary, tunable polyelectrolyte complex fluids driven by complex coacervation. Macromolecules 2014, 47 (9), 3076-3085 DOI: 10.1021/ma500245j.

(15) Perry, S. L.; Neumann, S. G.; Neumann, T.; Cheng, K.; Ni, J.; Weinstein, J. R.; Schaffer, D. V.; Tirrell, M. Challenges in nucleic acid-lipid films for transfection. AIChE J. 2013, 59 (9), 3203-3213 DOI: 10.1002/aic.14198. 
(16) Priftis, D.; Megley, K.; Laugel, N.; Tirrell, M. Complex coacervation of poly(ethyleneimine)/polypeptide aqueous solutions: thermodynamic and rheological characterization. $J$. Colloid Interface Sci. 2013, 398, 39-50 DOI: 10.1016/j.jcis.2013.01.055.

(17) Chollakup, R.; Smitthipong, W.; Eisenbach, C. D.; Tirrell, M. Phase Behavior and Coacervation of Aqueous Poly(acrylic acid)-Poly(allylamine) Solutions. Macromolecules 2010, 43 (5), 2518-2528 DOI: 10.1021/ma902144k.

(18) Chollakup, R.; Beck, J. B.; Dirnberger, K.; Tirrell, M.; Eisenbach, C. D. Polyelectrolyte molecular weight and salt effects on the phase behavior and coacervation of aqueous solutions of poly(acrylic acid) sodium salt and poly(allylamine) hydrochloride. Macromolecules 2013, 46 (6), 2376-2390 DOI: 10.1021/ma202172q.

(19) Priftis, D.; Farina, R.; Tirrell, M. Interfacial Energy of Polypeptide Complex Coacervates Measured via Capillary Adhesion †. Langmuir 2012, 28 (23), 8721-8729 DOI: 10.1021/la300769d.

(20) Priftis, D.; Tirrell, M. Phase behaviour and complex coacervation of aqueous polypeptide solutions. Soft Matter 2012, 8 (36), 9396-9405 DOI: 10.1039/C2SM25604E.

(21) Priftis, D.; Laugel, N.; Tirrell, M. Thermodynamic characterization of polypeptide complex coacervation. Langmuir 2012, 28 (45), 15947-15957 DOI: 10.1021/la302729r.

(22) Xu, A. Y.; Melton, L. D.; Ryan, T. M.; Mata, J. P.; Rekas, A.; Williams, M. A. K.; McGillivray, D. J. Effects of polysaccharide charge pattern on the microstructures of betalactoglobulin-pectin complex coacervates, studied by SAXS and SANS. Food Hydrocolloids 2018, 77, 952-963 DOI: 10.1016/j.foodhyd.2017.11.045.

(23) Xiong, W.; Ren, C.; Tian, M.; Yang, X.; Li, J.; Bin Li. Complex coacervation of ovalbumin-carboxymethylcellulose assessed by isothermal titration calorimeter and rheology: Effect of ionic strength and charge density of polysaccharide. Food Hydrocolloids 2017, 73, 41-50 DOI: 10.1016/j.foodhyd.2017.06.031.

(24) de Souza, V. B.; Thomazini, M.; Barrientos, M. A. E.; Nalin, C. M.; Ferro-Furtado, R.; Genovese, M. I.; Favaro-Trindade, C. S. Functional properties and encapsulation of a proanthocyanidin-rich cinnamon extract (Cinnamomum zeylanicum) by complex coacervation using gelatin and different polysaccharides. Food Hydrocolloids 2017, 1-10 DOI: 10.1016/j.foodhyd.2017.09.040.

(25) Frankel, E. A.; Bevilacqua, P. C.; Keating, C. D. Polyamine/Nucleotide coacervates provide strong compartmentalization of $\mathrm{Mg} 2+$, nucleotides, and RNA. Langmuir 2016, 32 (8), 2041-2049 DOI: 10.1021/acs.langmuir.5b04462.

(26) Knaapila, M.; Costa, T.; Garamus, V. M.; Kraft, M.; Drechsler, M.; Scherf, U.; Burrows, H. D. Polyelectrolyte complexes of a cationic all conjugated fluorene-thiophene diblock copolymer with aqueous DNA. J. Phys. Chem. B 2015, 119 (7), 3231-3241 DOI: 10.1021/jp5110032.

(27) Arfin, N.; Aswal, V. K.; Bohidar, H. B. Overcharging, thermal, viscoelastic and hydration properties of DNA-gelatin complex coacervates: pharmaceutical and food industries. $R S C$ $A d v$. 2014, 4 (23), 11705-11709 DOI: 10.1039/c3ra46618c.

(28) Tang, T. Y. D.; Antognozzi, M.; Vicary, J. A.; Perriman, A. W.; Mann, S. Small-molecule uptake in membrane-free peptide/nucleotide protocells. Soft Matter 2013, 9 (31), 76477656 DOI: $10.1039 / \mathrm{c} 3 \mathrm{sm} 50726 \mathrm{~b}$.

(29) Williams, D. S.; Koga, S.; Hak, C. R. C.; Majrekar, A.; Patil, A. J.; Perriman, A. W.; 
Mann, S. Polymer/nucleotide droplets as bio-inspired functional micro-compartments. Soft Matter 2012, 8 (22), 6004-6011 DOI: 10.1039/c2sm25184a.

(30) Koga, S.; Williams, D. S.; Perriman, A. W.; Mann, S. Peptide-nucleotide microdroplets as a step towards a membrane-free protocell model. Nat Chem 2011, 3 (9), 720-724 DOI: 10.1038/nchem.1110.

(31) Kawamura, A.; Harada, A.; Kono, K.; Kataoka, K. Self-Assembled Nano-Bioreactor from Block Ionomers with Elevated and Stabilized Enzymatic Function. Bioconjugate Chem. 2007, 18 (5), 1555-1559 DOI: 10.1021/bc070029t.

(32) Jaturanpinyo, M.; Harada, A.; Yuan, X.; Kataoka, K. Preparation of Bionanoreactor Based on Core-Shell Structured Polyion Complex Micelles Entrapping Trypsin in the Core Cross-Linked with Glutaraldehyde. Bioconjugate Chem. 2004, 15 (2), 344-348 DOI: $10.1021 / \mathrm{bc} 034149 \mathrm{~m}$.

(33) Harada, A.; Kataoka, K. Pronounced activity of enzymes through the incorporation into the core of polyion complex micelles made from charged block copolymers. J. Controlled Release 2001, 72 (1-3), 85-91 DOI: 10.1016/S0168-3659(01)00264-4.

(34) Kataoka, K.; Harada, A.; Nagasaki, Y. Block copolymer micelles for drug delivery: design, characterization and biological significance. Adv. Drug Delivery Rev. 2001, 47, 113-131.

(35) Harada, A.; Kataoka, K. Novel Polyion Complex Micelles Entrapping Enzyme Molecules in the Core. 2. Characterization of the Micelles Prepared at Nonstoichiometric Mixing Ratios. Langmuir 1999, 15 (12), 4208-4212 DOI: 10.1021/la981087t.

(36) Harada, A.; Kataoka, K. Novel Polyion Complex Micelles Entrapping Enzyme Molecules in the Core: Preparation of Narrowly-Distributed Micelles from Lysozyme and Poly(ethylene glycol)-Poly(aspartic acid) Block Copolymer in Aqueous Medium. Macromolecules 1998, 31, 288-294.

(37) Harada, A.; Kataoka, K. Formation of Polyion Complex Micelles in an Aqueous Milieu from a Pair of Oppositely-Charged Block Copolymers with Poly(ethylene glycol) Segments. Macromolecules 1995, 28, 5294-5299.

(38) Voets, I. K.; de Keizer, A.; Cohen Stuart, M. A. Complex coacervate core micelles. Adv. Colloid Interface Sci. 2009, 147-148 (C), 300-318 DOI: 10.1016/j.cis.2008.09.012.

(39) Kayitmazer, A. B.; Seyrek, E.; Dubin, P. L.; Staggemeier, B. A. Influence of Chain Stiffness on the Interaction of Polyelectrolytes with Oppositely Charged Micelles and Proteins. J. Phys. Chem. B 2003, 107 (32), 8158-8165 DOI: 10.1021/jp034065a.

(40) Kalantar, T. H.; Tucker, C. J.; Zalusky, A. S.; Boomgaard, T. A.; Wilson, B. E.; Ladika, M.; Jordan, S. L.; Li, W. K.; Zhang, X.; Goh, C. G. High throughput workflow for coacervate formation and characterization in shampoo systems. J. Cosmet. Sci. 2007, 58, 375-383.

(41) Hu, D.; Chou, K. C. Re-evaluating the surface tension analysis of polyelectrolytesurfactant mixtures using phase-sensitive sum frequency generation spectroscopy. $\mathrm{J} \mathrm{Am}$ Chem Soc 2014, 136 (43), 15114-15117 DOI: 10.1021/ja5049175.

(42) Nejati, M. M.; Khaledi, M. G. Perfluoro-alcohol-induced complex coacervates of polyelectrolyte-surfactant mixtures: Phase behavior and analysis. Langmuir 2015, 31 (20), 5580-5589 DOI: 10.1021/acs.langmuir.5b00444.

(43) Szczepanowicz, K.; Bazylińska, U.; Pietkiewicz, J.; Szyk-Warszyńska, L.; Wilk, K. A.; 
Warszyński, P. Biocompatible long-sustained release oil-core polyelectrolyte nanocarriers: From controlling physical state and stability to biological impact. Adv. Colloid Interface Sci. 2015, 222 (C), 678-691 DOI: 10.1016/j.cis.2014.10.005.

(44) Wang, Y.; Kimura, K.; Huang, Q.; Dubin, P. L.; Jaeger, W. Effects of Salt on Polyelectrolyte-Micelle Coacervation. Macromolecules 1999, 32 (21), 7128-7134 DOI: 10.1021/ma990972v.

(45) Wang, W.; Mauroy, H.; Zhu, K.; Knudsen, K. D.; Kjøniksen, A.-L.; Nyström, B.; Sande, S. A. Complex coacervate micelles formed by a C18-capped cationic triblock thermoresponsive copolymer interacting with SDS. Soft Matter 2012, 8 (45), 11514 11525 DOI: $10.1039 / \mathrm{c} 2 \mathrm{sm} 26567 \mathrm{~b}$.

(46) Karimi, F.; Qazvini, N. T.; Namivandi-Zangeneh, R. Fish gelatin/laponite biohybrid elastic coacervates: a complexation kinetics-structure relationship study. Int. J. Biol. Macromol. 2013, 61, 102-113 DOI: 10.1016/j.ijbiomac.2013.06.054.

(47) Pawar, N.; Bohidar, H. B. Anisotropic domain growth and complex coacervation in nanoclay-polyelectrolyte solutions. Adv. Colloid Interface Sci. 2011, 167 (1-2), 12-23 DOI: 10.1016/j.cis.2011.06.007.

(48) Krogstad, D. V.; Lynd, N. A.; Choi, S.-H.; Spruell, J. M.; Hawker, C. J.; Kramer, E. J.; Tirrell, M. V. Effects of polymer and salt concentration on the structure and properties of triblock copolymer coacervate hydrogels. Macromolecules 2013, 46 (4), 1512-1518 DOI: 10.1021/ma302299r.

(49) Krogstad, D. V.; Choi, S.-H.; Lynd, N. A.; Audus, D. J.; Perry, S. L.; Gopez, J. D.; Hawker, C. J.; Kramer, E. J.; Tirrell, M. V. Small angle neutron scattering study of complex coacervate micelles and hydrogels formed from ionic diblock and triblock copolymers. J. Phys. Chem. B 2014, 118 (45), 13011-13018 DOI: 10.1021/jp509175a.

(50) Krogstad, D. V.; Lynd, N. A.; Miyajima, D.; Gopez, J.; Hawker, C. J.; Kramer, E. J.; Tirrell, M. V. Structural evolution of polyelectrolyte complex core micelles and orderedphase bulk materials. Macromolecules 2014, 47 (22), 8026-8032 DOI: 10.1021/ma5017852.

(51) Hunt, J. N.; Feldman, K. E.; Lynd, N. A.; Deek, J.; Campos, L. M.; Spruell, J. M.; Hernandez, B. M.; Kramer, E. J.; Hawker, C. J. Tunable, High Modulus Hydrogels Driven by Ionic Coacervation. Adv. Mater. 2011, 23 (20), 2327-2331 DOI: 10.1002/adma.201004230.

(52) Stewart-Sloan, C. R.; Olsen, B. D. Protonation-induced microphase separation in thin films of a polyelectrolyte-hydrophilic diblock copolymer. ACS Macro Lett. 2014, 3 (5), 410-414 DOI: 10.1021/mz400650q.

(53) Kim, B.; Lam, C. N.; Olsen, B. D. Nanopatterned Protein Films Directed by Ionic Complexation with Water-Soluble Diblock Copolymers. Macromolecules 2012, 45 (11), 4572-4580 DOI: 10.1021/ma2024914.

(54) Wu, F.-G.; Jiang, Y.-W.; Chen, Z.; Yu, Z.-W. Folding behaviors of protein (lysozyme) confined in polyelectrolyte complex micelle. Langmuir 2016, 32 (15), 3655-3664 DOI: 10.1021/acs.langmuir.6b00235.

(55) Ishii, S.; Kaneko, J.; Nagasaki, Y. Development of a long-acting, protein-loaded, redoxactive, injectable gel formed by a polyion complex for local protein therapeutics. Biomaterials 2016, 84 (C), 210-218 DOI: 10.1016/j.biomaterials.2016.01.029. 
(56) Hwang, D. S.; Waite, J. H.; Tirrell, M. Promotion of osteoblast proliferation on complex coacervation-based hyaluronic acid-recombinant mussel adhesive protein coatings on titanium. Biomaterials 2010, 31 (6), 1080-1084 DOI: 10.1016/j.biomaterials.2009.10.041.

(57) Wang, W.; Xu, Y.; Li, A.; Li, T.; Liu, M.; Klitzing, von, R.; Ober, C. K.; Kayitmazer, A. B.; Li, L.; Guo, X. Zinc induced polyelectrolyte coacervate bioadhesive and its transition to a self-healing hydrogel. $R S C A d v$. 2015, 5 (82), 66871-66878 DOI: 10.1039/C5RA11915D.

(58) Winslow, B. D.; Shao, H.; Stewart, R. J.; Tresco, P. A. Biocompatibility of adhesive complex coacervates modeled after the sandcastle glue of Phragmatopoma californica for craniofacial reconstruction. Biomaterials 2010, 31 (36), 9373-9381 DOI: 10.1016/j.biomaterials.2010.07.078.

(59) Favi, P. M.; Yi, S.; Lenaghan, S. C.; Xia, L.; Zhang, M. Inspiration from the natural world: from bio-adhesives to bio-inspired adhesives. J. Adhes. Sci. Technol. 2013, 28 (34), 290-319 DOI: 10.1080/01694243.2012.691809.

(60) Mann, L. K.; Papanna, R.; Moise, K. J., Jr; Byrd, R. H.; Popek, E. J.; Kaur, S.; Tseng, S. C. G.; Stewart, R. J. Fetal membrane patch and biomimetic adhesive coacervates as a sealant for fetoscopic defects. Acta Biomater. 2012, 8 (6), 2160-2165 DOI: 10.1016/j.actbio.2012.02.014.

(61) Lim, S.; Choi, Y. S.; Kang, D. G.; Song, Y. H.; Cha, H. J. The adhesive properties of coacervated recombinant hybrid mussel adhesive proteins. Biomaterials 2010, 31 (13), 3715-3722 DOI: 10.1016/j.biomaterials.2010.01.063.

(62) Hwang, D. S.; Zeng, H.; Srivastava, A.; Krogstad, D. V.; Tirrell, M.; Israelachvili, J. N.; Waite, J. H. Viscosity and interfacial properties in a mussel-inspired adhesive coacervate. Soft Matter 2010, 6 (14), 3232-3235 DOI: 10.1039/c002632h.

(63) Hwang, D. S.; Zeng, H.; Lu, Q.; Israelachvili, J.; Waite, J. H. Adhesion mechanism in a DOPA-deficient foot protein from green mussels. Soft Matter 2012, 8 (20), 5640-5649 DOI: $10.1039 / \mathrm{c} 2 \mathrm{sm} 25173 \mathrm{f}$.

(64) Kaur, S.; Weerasekare, G. M.; Stewart, R. J. Multiphase Adhesive Coacervates Inspired by the Sandcastle Worm. ACS Appl. Mater. Interfaces 2011, 3 (4), 941-944 DOI: 10.1021/am200082v.

(65) Ahn, B. K.; Das, S.; Linstadt, R.; Kaufman, Y.; Martinez-Rodriguez, N. R.; Mirshafian, R.; Kesselman, E.; Talmon, Y.; Lipshutz, B. H.; Israelachvili, J. N.; et al. Highperformance mussel-inspired adhesives of reduced complexity. Nat Commun 2015, 6 (1), 8663 DOI: $10.1038 /$ ncomms9663.

(66) Stewart, R. J.; Wang, C. S.; Shao, H. Complex coacervates as a foundation for synthetic underwater adhesives. Adv. Colloid Interface Sci. 2011, 167 (1-2), 85-93 DOI: 10.1016/j.cis.2010.10.009.

(67) Choi, Y. S.; Kang, D. G.; Lim, S.; Yang, Y. J.; Kim, C. S.; Cha, H. J. Recombinant mussel adhesive protein fp-5 (MAP fp-5) as a bulk bioadhesive and surface coating material. Biofouling 2011, 27 (7), 729-737 DOI: 10.1080/08927014.2011.600830.

(68) Shao, H.; Bachus, K. N.; Stewart, R. J. A Water-Borne Adhesive Modeled after the Sandcastle Glue of P. californica. Macromol. Biosci. 2009, 9 (5), 464-471 DOI: 10.1002/mabi.200800252.

(69) Lim, S.; Moon, D.; Kim, H. J.; Seo, J. H.; Kang, I. S.; Cha, H. J. Interfacial tension of 
complex coacervated mussel adhesive protein according to the Hofmeister series. Langmuir 2014, 30 (4), 1108-1115 DOI: 10.1021/la403680z.

(70) Shao, H.; Weerasekare, G. M.; Stewart, R. J. Controlled curing of adhesive complex coacervates with reversible periodate carbohydrate complexes. J. Biomed. Mater. Res., Part $A$ 2011, $97 A$ (1), 46-51 DOI: 10.1002/jbm.a.33026.

(71) Farrar, D. F. Bone adhesives for trauma surgery A review of challenges and developments. Int. J. Adhes. Adhes. 2012, 33 (C), 89-97 DOI: 10.1016/j.ijadhadh.2011.11.009.

(72) Pippa, N.; Karayianni, M.; Pispas, S.; Demetzos, C. Complexation of cationic-neutral block polyelectrolyte with insulin and in vitro release studies. Int. J. Pharm. 2015, 491 (12), 136-143 DOI: 10.1016/j.ijpharm.2015.06.013.

(73) Pippa, N.; Kalinova, R.; Dimitrov, I.; Pispas, S.; Demetzos, C. Insulin/poly(ethylene glycol)- block-poly( 1-lysine) Complexes: Physicochemical Properties and Protein Encapsulation. J. Phys. Chem. B 2015, 119 (22), 6813-6819 DOI: 10.1021/acs.jpcb.5b01664.

(74) Nolles, A.; Westphal, A. H.; de Hoop, J. A.; Fokkink, R. G.; Kleijn, J. M.; van Berkel, W. J. H.; Borst, J. W.; Westphal, A. H. Encapsulation of GFP in complex coacervate core micelles. Biomacromolecules 2015, 16 (5), 1542-1549 DOI: 10.1021/acs.biomac.5b00092.

(75) Lindhoud, S.; de Vries, R.; Norde, W.; Cohen Stuart, M. A. Structure and Stability of Complex Coacervate Core Micelles with Lysozyme. Biomacromolecules 2007, 8 (7), 2219-2227 DOI: 10.1021/bm0700688.

(76) Lindhoud, S.; Claessens, M. M. A. E. Accumulation of small protein molecules in a macroscopic complex coacervate. Soft Matter 2016, 12 (2), 408-413 DOI: 10.1039/C5SM02386F.

(77) Chen, W. C. W.; Lee, B. G.; Park, D. W.; Kim, K.; Chu, H.; Kim, K.; Huard, J.; Wang, Y. Controlled dual delivery of fibroblast growth factor-2 and Interleukin-10 by heparin-based coacervate synergistically enhances ischemic heart repair. Biomaterials 2015, 72 (c), 138151 DOI: 10.1016/j.biomaterials.2015.08.050.

(78) Kishimura, A.; Koide, A.; Osada, K.; Yamasaki, Y.; Kataoka, K. Encapsulation of Myoglobin in PEGylated Polyion Complex Vesicles Made from a Pair of Oppositely Charged Block Ionomers: A Physiologically Available Oxygen Carrier. Angew. Chem. Int. Ed. 2007, 46 (32), 6085-6088 DOI: 10.1002/anie.200701776.

(79) Lindhoud, S.; de Vries, R.; Schweins, R.; Cohen Stuart, M. A.; Norde, W. Salt-induced release of lipase from polyelectrolyte complex micelles. Soft Matter 2009, 5 (1), 242-250 DOI: $10.1039 / \mathrm{B} 811640 \mathrm{G}$.

(80) Lindhoud, S.; Norde, W.; Cohen Stuart, M. A. Reversibility and Relaxation Behavior of Polyelectrolyte Complex Micelle Formation. J. Phys. Chem. B 2009, 113 (16), 5431-5439 DOI: 10.1021/jp809489f.

(81) Chu, H.; Gao, J.; Chen, C.-W.; Huard, J.; Wang, Y. Injectable fibroblast growth factor-2 coacervate for persistent angiogenesis. PNAS 2011, 108 (33), 13444-13449 DOI: 10.1073/pnas.1110121108.

(82) Johnson, N. R.; Ambe, T.; Wang, Y. Lysine-based polycation:heparin coacervate for controlled protein delivery. Acta Biomater. 2014, 10 (1), 40-46 DOI:

10.1016/j.actbio.2013.09.012. 
(83) Chu, H.; Chen, C.-W.; Huard, J.; Wang, Y. The effect of a heparin-based coacervate of fibroblast growth factor- 2 on scarring in the infarcted myocardium. Biomaterials 2013, 34 (6), 1747-1756 DOI: 10.1016/j.biomaterials.2012.11.019.

(84) Yen, J.; Ying, H.; Wang, H.; Yin, L.; Uckun, F.; Cheng, J. CD44 mediated nonviral gene delivery into human embryonic stem cells via hyaluronic-acid-coated nanoparticles. $A C S$ Biomater. Sci. Eng. 2016, 2 (3), 326-335 DOI: 10.1021/acsbiomaterials.5b00393.

(85) Kuo, C.-H.; Leon, L.; Chung, E. J.; Huang, R.-T.; Sontag, T. J.; Reardon, C. A.; Getz, G. S.; Tirrell, M.; Fang, Y. Inhibition of atherosclerosis-promoting microRNAs via targeted polyelectrolyte complex micelles. J. Mater. Chem. B 2014, 2, 8142-8153 DOI: 10.1039/C4TB00977K.

(86) Aumiller, W. M., Jr; Keating, C. D. Phosphorylation-mediated RNA/peptide complex coacervation as a model for intracellular liquid organelles. Nat Chem 2015, 8 (2), 129-137 DOI: $10.1038 /$ nchem.2414.

(87) Jin, K.-M.; Kim, Y.-H. Injectable, thermo-reversible and complex coacervate combination gels for protein drug delivery. J. Controlled Release 2008, 127 (3), 249-256 DOI: 10.1016/j.jconrel.2008.01.015.

(88) Kinoh, H.; Miura, Y.; Chida, T.; Liu, X.; Mizuno, K.; Fukushima, S.; Morodomi, Y.; Nishiyama, N.; Cabral, H.; Kataoka, K. Nanomedicines eradicating cancer stem-like cells in vivo by $\mathrm{pH}$-triggered intracellular cooperative action of loaded drugs. ACS Nano 2016, 10 (6), 5643-5655 DOI: 10.1021/acsnano.6b00900.

(89) Anraku, Y.; Kishimura, A.; Kamiya, M.; Tanaka, S.; Nomoto, T.; Toh, K.; Matsumoto, Y.; Fukushima, S.; Sueyoshi, D.; Kano, M. R.; et al. Systemically injectable enzymeloaded polyion complex vesicles as in vivo nanoreactors functioning in tumors. Angew. Chem. 2015, 128 (2), 570-575 DOI: 10.1002/ange.201508339.

(90) Schoonen, L.; van Hest, J. C. M. Compartmentalization approaches in soft matter science: From nanoreactor development to organelle mimics. Adv. Mater. 2015, 28 (6), 1109-1128 DOI: 10.1002/adma.201502389.

(91) Lv, K.; Perriman, A. W.; Mann, S. Photocatalytic multiphase micro-droplet reactors based on complex coacervation. Chem. Commun. 2015, 51 (41), 8600-8602 DOI: 10.1039/C5CC01914A.

(92) Hyman, A. A.; Simons, K. Beyond Oil and Water--Phase Transitions in Cells. Science 2012, 337 (6098), 1047-1049 DOI: 10.1126/science.1223728.

(93) Hyman, A. A.; Brangwynne, C. P. Beyond Stereospecificity: Liquids and Mesoscale Organization of Cytoplasm. Dev. Cell 2011, 21 (1), 14-16 DOI:

10.1016/j.devcel.2011.06.013.

(94) Weber, S. C.; Brangwynne, C. P. Getting RNA and Protein in Phase. Cell 2012, 149 (6), 1188-1191 DOI: 10.1016/j.cell.2012.05.022.

(95) Elbaum-Garfinkle, S.; Kim, Y.; Szczepaniak, K.; Chen, C. C.-H.; Eckmann, C. R.; Myong, S.; Brangwynne, C. P. The disordered P granule protein LAF-1 drives phase separation into droplets with tunable viscosity and dynamics. PNAS 2015, 112 (23), 7189-7194 DOI: $10.1073 /$ pnas. 1504822112.

(96) Kato, M.; Han, T. W.; Xie, S.; Shi, K.; Du, X.; Wu, L. C.; Mirzaei, H.; Goldsmith, E. J.; Longgood, J.; Pei, J.; et al. Cell-free Formation of RNA Granules: Low Complexity Sequence Domains Form Dynamic Fibers within Hydrogels. Cell 2012, 149 (4), 753-767 
DOI: 10.1016/j.cell.2012.04.017.

(97) Eulalio, A.; Behm-Ansmant, I.; Izaurralde, E. P bodies: at the crossroads of posttranscriptional pathways. Nat. Rev. Mol. Cell Biol. 2007, 8 (1), 9-22 DOI: $10.1038 / \mathrm{nrm} 2080$.

(98) Han, T. W.; Kato, M.; Xie, S.; Wu, L. C.; Mirzaei, H.; Pei, J.; Chen, M.; Xie, Y.; Allen, J.; Xiao, G.; et al. Cell-free Formation of RNA Granules: Bound RNAs Identify Features and Components of Cellular Assemblies. Cell 2012, 149 (4), 768-779 DOI:

10.1016/j.cell.2012.04.016.

(99) Jia, T. Z.; Hentrich, C.; Szostak, J. W. Rapid RNA exchange in aqueous two-phase system and coacervate droplets. Origins Life Evol. Biospheres 2014, 44 (1), 1-12 DOI: 10.1007/s11084-014-9355-8.

(100) Li, P.; Banjade, S.; Cheng, H.-C.; Kim, S.; Chen, B.; Guo, L.; Llaguno, M.; Hollingsworth, J. V.; King, D. S.; Banani, S. F.; et al. Phase transitions in the assembly of multivalent signalling proteins. Nature 2012, 483 (7389), 336-340 DOI: 10.1038/nature10879.

(101) Walter, H. Consequences of Phase Separation in Cytoplasm. Int. Rev. Cytol. 1999, 192, 331-343.

(102) Brangwynne, C. P.; Mitchison, T. J.; Hyman, A. A. Active liquid-like behavior of nucleoli determines their size and shape in Xenopus laevis oocytes. PNAS 2011, 108 (11), 43344339 DOI: $10.1073 /$ pnas.1017150108.

(103) Brangwynne, C. P.; Eckmann, C. R.; Courson, D. S.; Rybarska, A.; Hoege, C.; Gharakhani, J.; Julicher, F.; Hyman, A. A. Germline P Granules Are Liquid Droplets That Localize by Controlled Dissolution/Condensation. Science 2009, 324 (5935), 1729-1732 DOI: $10.1126 /$ science.1172046.

(104) Brangwynne, C. P. Phase transitions and size scaling of membrane-less organelles. J. Cell. Biol. 2013, 203 (6), 875-881 DOI: 10.1083/jcb.201308087.

(105) Zhang, H.; Elbaum-Garfinkle, S.; Langdon, E. M.; Taylor, N.; Occhipinti, P.; Bridges, A. A.; Brangwynne, C. P.; Gladfelter, A. S. RNA controls PolyQ protein phase transitions. Mol. Cell 2015, 60 (2), 220-230 DOI: 10.1016/j.molcel.2015.09.017.

(106) Lin, Y.; Protter, D. S. W.; Rosen, M. K.; Parker, R. Formation and maturation of phaseseparated liquid droplets by RNA-binding proteins. Mol. Cell 2015, 60 (2), 208-219 DOI: 10.1016/j.molcel.2015.08.018.

(107) Fromm, S. A.; Kamenz, J.; Nöldeke, E. R.; Neu, A.; Zocher, G.; Sprangers, R. In vitro reconstitution of a cellular phase-transition process that Involves the mRNA decapping machinery. Angew. Chem. Int. Ed. 2014, 53 (28), 7354-7359 DOI: 10.1002/anie.201402885.

(108) Patel, A.; Lee, H. O.; Jawerth, L.; Maharana, S.; Jahnel, M.; Hein, M. Y.; Stoynov, S.; Mahamid, J.; Saha, S.; Franzmann, T. M.; et al. A liquid-to-solid phase transition of the ALS protein FUS accelerated by disease mutation. Cell 2015, 162 (5), 1066-1077 DOI: 10.1016/j.cell.2015.07.047.

(109) Burke, K. A.; Janke, A. M.; Rhine, C. L.; Fawzi, N. L. Residue-by-residue Vvew of in vitro FUS granules that bind the C-terminal domain of RNA polymerase II. Mol. Cell 2015, 60 (2), 231-241 DOI: 10.1016/j.molcel.2015.09.006.

(110) Radhakrishna, M.; Basu, K.; Liu, Y.; Shamsi, R.; Perry, S. L.; Sing, C. E. Molecular 
Connectivity and Correlation Effects on Polymer Coacervation. Macromolecules 2017, 50 (7), 3030-3037 DOI: 10.1021/acs.macromol.6b02582.

(111) Liu, Y.; Momani, B.; Winter, H. H.; Perry, S. L. Rheological characterization of liquid-tosolid transitions in bulk polyelectrolyte complexes. Soft Matter 2017, 13, 7332-7340 DOI: 10.1039/C7SM01285C.

(112) Spruijt, E.; Westphal, A. H.; Borst, J. W.; Cohen Stuart, M. A.; van der Gucht, J. Binodal Compositions of Polyelectrolyte Complexes. Macromolecules 2010, 43 (15), 6476-6484 DOI: $10.1021 / \mathrm{ma101031t}$.

(113) Huang, J.; Morin, F. J.; Laaser, J. E. Charge-Density-Dominated Phase Behavior and Viscoelasticity of Polyelectrolyte Complex Coacervates. Macromolecules 2019, 52 (13), 4957-4967 DOI: 10.1021/acs.macromol.9b00036.

(114) Lou, J.; Friedowitz, S.; Qin, J.; Xia, Y. Tunable Coacervation of Well-Defined Homologous Polyanions and Polycations by Local Polarity. ACS Cent Sci 2019, 5 (3), 549-557 DOI: 10.1021/acscentsci.8b00964.

(115) Kapelner, R. A.; Obermeyer, A. C. Ionic polypeptide tags for protein phase separation. Chem. Sci. 2019, 10 (9), 2700-2707 DOI: 10.1039/C8SC04253E.

(116) Cummings, C. S.; Obermeyer, A. C. Phase Separation Behavior of Supercharged Proteins and Polyelectrolytes. Biochemistry 2018, 57 (3), 314-323 DOI: 10.1021/acs.biochem.7b00990.

(117) Comert, F.; Dubin, P. L. Liquid-liquid and liquid-solid phase separation in proteinpolyelectrolyte systems. Adv. Colloid Interface Sci. 2017, 239, 213-217 DOI: 10.1016/j.cis.2016.08.005.

(118) Niu, F.; Dong, Y.; Shen, F.; Wang, J.; Liu, Y.; Su, Y.; Xu, R.; Wang, J.; Yang, Y. Phase separation behavior and structural analysis of ovalbumin-gum arabic complex coacervation. Food Hydrocolloids 2015, 43 (C), 1-7 DOI: 10.1016/j.foodhyd.2014.02.009.

(119) Takahashi, R.; Narayanan, T.; Sato, T. Growth Kinetics of Polyelectrolyte Complexes Formed from Oppositely-Charged Homopolymers Studied by Time-Resolved UltraSmall-Angle X - ray Scattering. J Phys Chem Lett 2017, 737-741 DOI: 10.1021/acs.jpclett.6b02957.

(120) Su, C.; Zhao, M.; Zhu, Z.; Zhou, J.; Wen, H.; Yin, Y.; Deng, Y.; Qiu, D.; Li, B.; Liang, D. Effect of Peptide Charge Distribution on the Structure and Kinetics of DNA Complex. Macromolecules 2015, 48 (3), 756-763 DOI: 10.1021/ma501901b.

(121) Salehi, A.; Desai, P. S.; Li, J.; Steele, C. A.; Larson, R. G. Relationship between Polyelectrolyte Bulk Complexation and Kinetics of Their Layer-by-Layer Assembly. Macromolecules 2015, 48, 400-409 DOI: 10.1021/ma502273a.

(122) Salvatore, D.; Croguennec, T.; Bouhallab, S.; Forge, V.; Nicolai, T. Kinetics and Structure during Self-Assembly of Oppositely Charged Proteins in Aqueous Solution. Biomacromolecules 2011, 12 (5), 1920-1926 DOI: 10.1021/bm200264m.

(123) Kuehn, F.; Fischer, K.; Schmidt, M. Kinetics of Complex Formation between DNA and Cationically Charged Cylindrical Brush Polymers Observed by Stopped Flow Light Scattering. Macromol. Rapid Commun. 2009, 30 (17), 1470-1476 DOI: 10.1002/marc.200900166.

(124) Kanai, S.; Muthukumar, M. Phase separation kinetics of polyelectrolyte solutions. J Chem 
Phys 2007, 127 (24), 244908-244914 DOI: 10.1063/1.2806299.

(125) Sato, H.; Seki, H. Kinetic Study on the Founcation of Polyelectrolyte Complexes. Poly(Llysine hydrobromide) ad Poly(L-glutamate sodium salt). Polymer J 1993, 25 (5), 529-533.

(126) Liu, X.; Chapel, J.-P.; Schatz, C. Structure, thermodynamic and kinetic signatures of a synthetic polyelectrolyte coacervating system. Adv. Colloid Interface Sci. 2017, 239 (C), 178-186 DOI: 10.1016/j.cis.2016.10.004.

(127) Liu, X.; Haddou, M.; Grillo, I.; Mana, Z.; Chapel, J.-P.; Schatz, C. Early stage kinetics of polyelectrolyte complex coacervation monitored through stopped-flow light scattering. Soft Matter 2016, 1-9 DOI: 10.1039/C6SM01979J.

(128) Turgeon, S. L.; Beaulieu, M.; Schmitt, C.; Sanchez, C. Protein-polysaccharide interactions: phase-ordering kinetics, thermodynamic and structural aspects. Curr. Opin. Colloid Interface Sci. 2003, 8, 401-414 DOI: 10.1016/S1359-0294(03)00093-1.

(129) Vitorazi, L.; Ould-Moussa, N.; Sekar, S.; Fresnais, J.; Loh, W.; Chapel, J. P.; Berret, J. F. Evidence of a two-step process and pathway dependency in the thermodynamics of poly(diallyldimethylammonium chloride)/poly(sodium acrylate) complexation. Soft Matter 2014, 10 (47), 9496-9505 DOI: 10.1039/C4SM01461H.

(130) Amblard, M.; Fehrentz, J.-A.; Martinez, J.; Subra, G. Methods and Protocols of Modern Solid Phase Peptide Synthesis. Molecular Biotechnology 2006, 33 (3), 239-254 DOI: 10.1385/MB:33:3:239.

(131) Chang, L.-W.; Lytle, T. K.; Radhakrishna, M.; Madinya, J. J.; Vélez, J.; Sing, C. E.; Perry, S. L. Sequence and entropy-based control of complex coacervates. Nat Commun 2017, 8, 1273 DOI: 10.1038/s41467-017-01249-1.

(132) Pacalin, N. M.; Leon, L.; Tirrell, M. Directing the phase behavior of polyelectrolyte complexes using chiral patterned peptides. Eur. Phys. J. Spec. Top. 2016, 225 (8-9), 18051815 DOI: 10.1140/epjst/e2016-60149-6.

(133) Kramer, J. R.; Deming, T. J. General Method for Purification of $\alpha$-Amino acid- Ncarboxyanhydrides Using Flash Chromatography. Biomacromolecules 2010, 11 (12), 3668-3672 DOI: 10.1021/bm101123k.

(134) Blocher McTigue, W. C.; Perry, S. L. Incorporation of Proteins into Complex Coacervates. Methods in Enzymology 2020, Submitted.

(135) Blocher McTigue, W. C.; Perry, S. L. Design Rules for Encapsulating Proteins into Complex Coacervates. Soft Matter 2019, 15, 3089-3103 DOI: 10.1039/C9SM00372J.

(136) Perry, S. L. Phase separation: Bridging polymer physics and biology. Curr. Opin. Colloid Interface Sci. 2019, 39, 86-97 DOI: 10.1016/j.cocis.2019.01.007.

(137) Liu, Y.; Winter, H. H.; Perry, S. L. Linear viscoelasticity of complex coacervates. Adv. Colloid Interface Sci. 2017, 239, 46-60 DOI: 10.1016/j.cis.2016.08.010.

(138) Rubinstein, M.; Colby, R. H. Polymer Physics; Oxford University Press, 2003.

(139) Liu, Y.; Chalarca, C. F. S.; Carmean, R. N.; Olson, R. A.; Madinya, J. J.; Sumerlin, B. S.; Sing, C. E.; Emerick, T.; Perry, S. L. Effect of Polymer Chemistry on the Linear Viscoelacticity of Complex Coacervates; 2020; $\mathrm{p}$ Submitted.

(140) Sun, J.; Perry, S. L.; Schiffman, J. D. Electrospinning Nanofibers from Chitosan/Hyaluronic Acid Complex Coacervates. Biomacromolecules 2019, 20, 41914198 DOI: 10.1021/acs.biomac.9b01072. 
(141) Spruijt, E.; Sprakel, J.; Lemmers, M.; Cohen Stuart, M. A.; van der Gucht, J. Relaxation Dynamics at Different Time Scales in Electrostatic Complexes: Time-Salt Superposition. Phys. Rev. Lett. 2010, 105 (20), 208301-208304 DOI: 10.1103/PhysRevLett.105.208301.

(142) Spruijt, E.; Cohen Stuart, M. A.; van der Gucht, J. Linear viscoelasticity of polyelectrolyte complex coacervates. Macromolecules 2013, 46 (4), 1633-1641 DOI: 10.1021/ma301730n.

(143) Wang, Q.; Schlenoff, J. B. The polyelectrolyte complex/coacervate continuum. Macromolecules 2014, 47 (9), 3108-3116 DOI: 10.1021/ma500500q.

(144) Schaaf, P.; Schlenoff, J. B. Saloplastics: Processing compact polyelectrolyte complexes. Adv. Mater. 2015, 27 (15), 2420-2432 DOI: 10.1002/adma.201500176.

(145) Sadman, K.; Wang, Q.; Chen, Y.; Keshavarz, B.; Jiang, Z.; Shull, K. R. Influence of Hydrophobicity on Polyelectrolyte Complexation. Macromolecules 2017, 50 (23), $9417-$ 9426 DOI: 10.1021/acs.macromol.7b02031.

(146) Hofmeister, F. Zur Lehre von der Wirkung der Salze. Archiv f experiment Pathol u Pharmakol 25, 1-30.

(147) Zhang, Y.; Cremer, P. S. Interactions between macromolecules and ions: the Hofmeister series. Curr. Opin. Chem. Biol. 2006, 10 (6), 658-663 DOI: 10.1016/j.cbpa.2006.09.020.

(148) Kunz, W.; Nostro, Lo, P.; Ninham, B. W. The present state of affairs with Hofmeister effects. Curr. Opin. Colloid Interface Sci. 2004, 9 (1-2), 1-18 DOI: 10.1016/j.cocis.2004.05.004.

(149) Collins, K. D. Ions from the Hofmeister Series and Osmolytes: Effects on Proteins in Solution and in the Crystallization Process. Methods 2004, 34 (3), 300-311 DOI: 10.1016/j.ymeth.2004.03.021.

(150) Salis, A.; Ninham, B. W. Models and mechanisms of Hofmeister effects in electrolyte solutions, and colloid and protein systems revisited. Chem. Soc. Rev. 2014, 43, 7358-7377 DOI: $10.1039 / \mathrm{C} 4 \mathrm{CS} 00144 \mathrm{C}$. 